\title{
Models for Supplier Selection and Risk Mitigation: A Holistic Approach
}

\section{Jiho Yoon}

Department of Management, College of Business Administration, Kansas State University, Manhattan, KS, USA

Phone: (785) 532-3691, Email: jihoyoon@ksu.edu

\section{Srinivas Talluri}

Department of Supply Chain Management, The Eli Broad Graduate School of Management, Michigan State University, East Lansing, MI, USA

Phone: (517) 432-6430, Email: talluri@broad.msu.edu

\section{Hakan Yildiz}

Department of Supply Chain Management, The Eli Broad Graduate School of Management, Michigan State University, East Lansing, MI, USA

Phone: (517) 432-6439, Email: yildiz@broad.msu.edu

\section{William Ho}

Department of Management and Marketing,

The University of Melbourne, Melbourne, Vic, Australia

Phone: +61 (903) 57569, Email: William.ho@unimelb.edu.au 


\section{Models for Supplier Selection and Risk Mitigation: A Holistic Approach}

With growing emphasis on supply risk, consideration of risk aspects in supplier selection has become an important issue faced by firms. While current literature has proposed a variety of tools and techniques for effective supplier selection, few approaches, if any, are proposed in incorporating risk mitigation strategies in supplier selection decisions. To this end, this paper fills this gap, by considering a variety of risk factors in supplier selection, which are both quantitative and qualitative in nature, and tests the efficacy of alternative risk mitigation strategies in this context. Moreover, we argue that both upstream and downstream risk mitigation strategies should be used simultaneously rather than focusing on a single type of strategy. We further argue that alignment between upstream and downstream risk mitigation strategies is critical in reducing risk. We utilize multi-objective optimization based simulation in building a decision model in the context of this problem setting. We consider data from an automotive parts manufacturer in demonstrating the application of our approach.

Keywords: Supply Chain Risk Management, Supplier Selection, Risk Mitigating Strategy, MultiObjective Optimization, Mathematical Models 


\section{Introduction}

Managing suppliers is one of the key issues in supply chain management (SCM) given that the cost of raw materials and component parts make up the primary cost of a product. Most manufacturing firms spend considerable amount of their sales revenue on supply procurement (Goffin et al., 2006), ranging from $60 \%$ to $80 \%$ of production cost (Dey et al., 2015). Selecting the right supplier not only reduces the purchasing costs significantly (Ghodsypour and O'Brien, 2001), but also contributes in product innovation and helps achieve effective production processes (Dey et al., 2015). Therefore, supplier selection is one of the critical issues in SCM for maintaining a competitive advantage. Traditionally, supplier selection has mainly focused on cost, but recent emphasis has also been on other important factors such as quality, delivery, flexibility, and social and environmental sustainability (Sarkis and Talluri, 2002; Amid et al., 2011; Lin, 2012; Scott et al., 2013; Scott et al., 2015). As a supply chain becomes more complex, extended, and globalized, firms become more and more dependent on their suppliers. This also entails a number of unexpected negative events, which makes supplier selection a more important and difficult task compared to the past. For instance, the catastrophic Thailand flooding of October 2011 affected the supply chains of computer manufacturers dependent on hard disks, and also disrupted the supply chains of Japanese automotive companies with plants in Thailand (Chopra and Sodhi, 2014). Similarly, the earthquake and Tsunamis that hit Japan in 2011 affected almost all major auto manufacturers globally, because of the many Japanese parts suppliers that were impacted significantly. The case of Ericsson is also a well-known incident where a fire at a Phillips semiconductor plant in 2000 led to Ericsson's \$400 million loss (Chopra and Sodhi 2004). Thus, in supplier selection, it is necessary to consider factors above and beyond cost from a risk management perspective. 
Supply chain risk management (SCRM) has been receiving increasing attention in both academic and practitioner circles. There is a continuous growth in the number of articles focusing on SCRM in the period between 2003-2013 (Ho et al., 2015). The number of articles published in 2003 is only 8, whereas it increased to 33 in 2013. Besides, there are already eight literature review articles surveying SCRM in the last decade (Tang, 2006; Rao and Goldsby, 2009; Tang and Musa, 2011; Colicchia and Strozzi, 2012; Sodhi et al., 2012; Fahimnia et al., 2015; Heckmann et al., 2015; Ho et al., 2015). Literature in this area has primarily focused on: i) identifying and categorizing risk drivers ${ }^{1}$ (Chopra and Sodhi, 2004; Kull and Talluri, 2008) ii) developing risk assessment techniques (Zsidisin et al., 2004; Wang et al., 2012; Aqlan and Lam, 2015) iii) defining risk mitigation strategies (Chopra and Sodhi, 2004; Faisal et al., 2006); and iv) evaluating risk management strategies (Talluri et al, 2014; Mohammaddust et al., 2017). It is not uncommon for companies in the same industry to face different types of risks, which leads them to emphasize and recognize that adapting tailored risk mitigation strategies is a key aspect for their success in a turbulent environment (Hauser, 2003; Chopra and Sodhi, 2004). Various risk mitigation strategies (including upstream and downstream risk mitigation strategies) have already been proposed by several researchers to address specific needs of companies. Among such risk mitigation strategies, companies are interested in efficient strategies that reduce risk without eroding profits (Talluri et al., 2013).

In this article, we address the issue of supplier selection and risk mitigation strategy selection in a simultaneous manner during a given planning horizon in a supply chain. We also argue that risk mitigation should be considered at the supplier selection phase with a combination of upstream and downstream risk mitigation strategies rather than separately focusing on applying a sole strategy. Extant literature studied the risk mitigation strategies and their effectiveness (e.g.,

\footnotetext{
${ }^{1}$ Risk drivers: factors such as events and conditions, which might increase the level of risk in a supply chain (Chopra and Sodhi, 2004; Jüttner et al., 2003)
} 
Chopra and Sodhi, 2004; Schmitt, 2011; Chopra and Sodhi, 2014). Not surprisingly, several of these strategies are closely related to the supplier selection issue for mitigating upstream risk such as having redundant suppliers. However, there is no previous work that addresses the potential synergy between mitigation strategies related to downstream risk (such as demand uncertainty) and supplier selection based mitigation strategies focusing on upstream risk (such as quality failure, supply quantity flexibility failure etc.). We conjecture that an alignment between upstream and downstream risk mitigation at the supplier selection stage can result in a more effective way to appease risk.

To this end, the contribution of this paper is two-fold. First, we propose models that integrate two important SCM issues: i) supplier selection and ii) risk mitigation strategy selection. The models demonstrate the reasons for the two aspects to be considered simultaneously rather than separately. Second, from a methodological perspective, we develop decision models that utilize a combination of multi-objective optimization and simulation approaches, for simultaneous consideration of a broad range of risk drivers, objectives, company's risk attitude, and order allocation factors. The multi-objective optimization allows the simultaneous consideration of cost and risk (Yildiz et al., 2015) and simulation enables us to achieve efficiency and effectiveness in deriving solutions under a given parameter set over a multi-period planning horizon (Jung et al., 2004). Thus, we expect that this combination of methodologies to provide a holistic solution to this problem environment.

The remainder of the paper is organized as follows. The next section reviews the related literature in the areas of supplier selection and risk mitigation. We then describe the problem and introduce representative risk mitigation strategies that are selected from the literature. The following 
section presents the mathematical models for supplier selection with the consideration of risk mitigation strategy selection and related analysis. Finally, we discuss the limitations of our approach and present future research directions.

\section{Literature Review}

This paper is related to two streams of literature: supplier selection and supply chain risk mitigation. Section 2.1 presents the relevant literature on supplier selection with risk consideration. Section 2.2 discusses the literature of both generic supply chain and specific supply risk mitigation strategies. Section 2.3 summarizes the knowledge gaps of the literature, and identifies the novelty of this paper.

\subsection{Supplier selection with risk consideration}

Supplier selection is a critical issue in SCM, since poor decisions can lead to various supply base problems such as late deliveries and/or high defects rates (Smeltzer and Siferd, 1998). It is also shown that supplier selection was the most influential factor for achieving long-term competitive advantage (González and Quesada, 2004; Spekman, 1988; Önüt et al., 2009). Moreover, as supply chains become global, a firm's supply chain risks begin to be influenced more by outside factors in addition to internal factors. Thus, in this study, supplier selection and its associated factors are viewed from a SCRM perspective.

Tomlin (2006) simplifies the risks into two groups in supplier selection, i.e., recurrent risks and disruption risks, and considers the case of one unreliable supplier and one reliable but more expensive supplier. He demonstrates that supplier diversification strategy is favored over an inventory reserve approach if unfavorable events are rare but long (disruption risk), whereas an inventory based approach is preferred if unfavorable events are frequent but short (recurrent risk). He further showed that supplier characteristics such as reliability and flexibility and the nature of 
risk (disruption or recurrent) are key for effective supplier selection. Other literature also presents similar findings and emphasizes the importance of decoupling recurrent risks and disruption risks, and the importance of supplier features such as reliability when managers are selecting suppliers (Chopra et al., 2007).

Ho et al. (2015) classify supply chain risks into seven categories and find that the most widely studied risk type is supply risk followed by demand risk, manufacturing risk, financial risk, macro risk, information risk, and transportation risk. Table 1 shows that a number of researchers studied the supplier selection problem with the consideration of a variety of supply risks. The risk factors considered in the supplier selection process include poor quality (Talluri and Narasimhan, 2003; Talluri et al., 2006; Fang et al., 2016), late delivery (Talluri and Narasimhan, 2003; Talluri et al., 2006; Fang et al., 2016), uncertain capacity (Kumar et al., 2006; Viswanadham and Samvedi, 2013), dispersed geographical location (Chan and Kumar, 2007), supplier failure (Kull and Talluri, 2008; Ravindran et al., 2010; Ruiz-Torres et al., 2013), supplier's financial stress (Lockamy III and McCormack, 2010), supply disruption (Wu and Olson, 2010; Meena et al., 2011; Sawik, 2014; ; Fang et al., 2016), poor supplier service (Wu et al., 2010; Chen and Wu, 2013), lack of supplier involvement (Chaudhuri et al., 2013), supplier's economic risk (Moghaddam, 2015; Rao et al., 2017), supplier's technology risk (Rao et al., 2017), supplier's information risk (Rao et al., 2017), supplier's management risk (Rao et al., 2017), supplier's environmental risk (Rao et al., 2017), supplier's societal risk (Rao et al., 2017), and supplier's ethical risk (Rao et al., 2017).

From Table 1, we can observe that there is no study focusing on both supplier selection and risk mitigation simultaneously. Instead, researchers simply considered particular risk factors together with some traditional criteria, such as cost, quality, delivery, service, and innovation for supplier evaluation and selection. For example, Kull and Talluri (2008) propose a decision support 
tool for supplier selection in the context of risk management by effectively integrating risk issues into supplier evaluation using a combination of analytical hierarchy process (AHP) and mathematical programming. Their approach supports managers in prioritizing supply chain objectives, identifying risk indicators, assessing the likelihood \& potential impact of negative events, and deriving risk coverage scores logically and rationally. The risk coverage score of an entity is defined as the degree of how well the entity can handle a variety of risks. Thus, the higher the risk coverage score, the more reliable the entity is.

Insert Table 1 Here

\subsection{Supplier chain risk mitigation}

The relationship between investment and its expected returns is a fundamental issue for businesses. We know that a set of actions, which provide higher returns and/or improved risk coverage abilities, require a certain amount of upfront investment costs. In the same vein, scholars state that investments in increasing reliability and responsiveness of supply chains could be viewed as buying insurance against the economic loss from potential disruptions (Hendricks and Singhal, 2005). However, investment in changes or development is itself inherently risky (Hallikas et al., 2004). Therefore, careful consideration of investment decisions is a necessary part of SCRM. In line with this logic, a conceptual framework that trades off risk mitigation investments, including the cost of management systems, against potential losses caused by supply chain risks arising from disruptions is proposed by Kleindorfer and Saad (2005). This investment evaluation approach for risk management may supplement the supplier selection approach. However, the existing investment evaluation approaches only focus on disruptions. Risk assessment process is generally composed of two dimensions, assessing the likelihood and impact of a potential problem, i.e., likelihood $\times$ impact. Based on this assessment process, even though recurrent risks have low impact, they 
have high likelihood, which makes recurrent risks equally important as disruptions. Thus, we also need to take recurrent risks into consideration while making investment decisions.

The extensive supply chain risk sources and the broad range of risk management approaches result in various risk mitigating strategies in supply chains. Some studies have sought to define generic supply chain risk-mitigating strategies by considering the strategic "fit" concept (Jüttner et al., 2003; Chopra and Sodhi, 2004). They note four types of risk mitigation strategies that can be adapted to supply chain contexts from five generic strategies introduced by earlier studies (Miller, 1992): (i) avoidance; (ii) control; (iii) cooperation; and (iv) flexibility (Jüttner et al., 2003). They roughly explain the suitability of each strategy with emphasis on the concept of "fit". The strategies are composed of different set of enablers that interact with each other (Faisal et al., 2006). Each enabler covers its own set of risk drivers and the interaction of enablers leads to the coverage of a variety of risk drivers across different enablers. In that context, Chopra and Sodhi (2004) focuses on categorizing risk drivers and possible risk mitigation strategies based on the interaction of individual risks: (i) add capacity; (ii) add inventory; (iii) have redundant suppliers; (iv) increase responsiveness; (v) increase flexibility; (vi) aggregate or pool demand; (vii) increase capacity; and (viii) have more customer accounts.

Researchers have focused on examining strategies for mitigating supply risks specifically using analytical and empirical approaches. Utilizing analytical methods, Tomlin (2006) tests four different risk mitigation strategies with an emphasis on supplier selection by applying a Markovian approach. In that study, it is assumed that supplier selection decision is made first and then a risk mitigation strategy can be utilized, thus resulting in sequential decision making. Talluri et al. (2013) also test the aforementioned seven risk mitigation strategies, except "have more customer accounts", each in isolation, by employing discrete event simulation. Some of these strategies are 
upstream focused, e.g., selecting and utilizing redundant suppliers, and others are downstream focused, e.g. increasing production capacity.

Similar to the case of analytical methods, there is no empirical study in this domain considering both supplier selection and risk mitigation simultaneously. Instead, empirical studies have demonstrated that supply risk can be mitigated by implementing behavior-based management techniques (Zsidisin and Ellram, 2003), building strategic supplier relationships (Giunipero and Eltantawy, 2004; Hallikas et al., 2005), early supplier involvement (Zsidisin and Smith, 2005), adopting business continuity planning as a formal risk management technique (Zsidisin et al., 2005), and reducing supply base complexity (Choi and Krause, 2006).

\subsection{Gaps}

There is an extensive amount of research focusing on the two related topics, supplier selection and risk mitigation, separately or sequentially. In Section 2.1 , we can observe that although researchers considered risk factors for supplier selection, they did not actually consider supplier selection and risk mitigation simultaneously. In Section 2.2, we can also note that there are no empirical studies that consider both supplier selection and risk mitigation simultaneously. Although analytical studies attempted to consider these aspects jointly, they treated them in a sequential or isolated manner.

In this study, we fill the above knowledge gaps by considering both upstream and downstream focused mitigation strategies simultaneously rather than sequentially in order to achieve a greater synergic effect. The superiority of simultaneous consideration over sequential comes from two sources. First advantage is fairly obvious, i.e., the solution space for a simultaneous optimization problem is at least as large as the sequential optimization. The second benefit is less obvious, which is related to the compatibility of strategies that are being considered simultaneously.

\section{Problem Description}


We consider a three-tier supply chain composed of a focal company (part manufacturer in automotive industry), potential suppliers and customers. The automotive industry provides a good context for studying various supply chain problems, including supplier selection and risk management, as many auto manufacturers operate in a JIT environment and expect very high customer service and high reliability from their suppliers even if that means extra costs (Yildiz et al., 2016). We assume that there are multiple customers, but one of these customers is more important than the rest and designated as the "main customer" (see Figure 1), which is quite common for automotive parts manufacturers.

\section{Insert Figure 1 Here}

Customer diversification is one of the most difficult missions for companies because significantly larger monetary and human resources are required to achieve multiple large customer accounts. Thus, the strategy to "have more customer accounts", i.e., having multiple large customer accounts, is possible only for a few big automotive part manufactures such as TRW and Bosch (Yildiz et al., 2010). With this assumption we consider a three-tier supply chain with multiple suppliers and a single customer from the focal company's perspective.

There are two conflicting goals that the focal company is trying to achieve simultaneously: cost minimization and risk minimization (or reliability maximization) through achieving a reliable flow of supplies from the supply base (upstream risk mitigation) while dealing with customer's demand uncertainty (downstream risk mitigation). We assume that each of the various potential suppliers have different levels of reliability. Thus, sourcing more from a reliable supplier decreases upstream risk and increases sourcing reliability. Similarly, in order to reduce downstream risk, the focal company might carry inventory to reduce (or avoid) shortages due to demand uncertainty or quality issues. Within this context, we consider four risk mitigation strategies, which have been 
also studied in the literature. Two strategies related to supplier selection, which can mitigate upstream risk: i) Acquire redundant supplier(s) (ARS) and ii) Have more flexible supplier(s) (HFS). Two other strategies related to internal capabilities, which can manage downstream risk: iii) Increase (manufacturing) capacity (IC) and iv) Increase inventory capacity (IV).

Insert Table 2 Here

Note that we exclude customer diversification related strategies (such as to "have more customer accounts" introduced by Chopra and Sodhi (2004)) because such strategies are only possible for a few large parts manufacturers in the automotive industry as we discussed previously. In addition, we are not considering strategies that are only applicable to multiple customers settings (such as to "aggregate or pool demand" introduced in Chopra and Sodhi (2004)) since the supply chain we consider has a single customer. Table 2 summarizes the strategies from the focal company's perspective.

The first two strategies (ARS and HFS) inherently contain the supplier selection aspect. However, the other two strategies (IC and IV) can be applied without modifying the existing supply base. In the following section, we first test if the strategies in Table 2 can reduce risk (increase reliability) and, at the same time, reduce cost (compared to base case, i.e., without applying any mitigation strategies). In addition, we investigate if the downstream risk mitigation strategies (IC and IV) should be considered along with upstream risk mitigation strategies (ARS and HFS) for better results.

\section{Mathematical Model}

Supplier selection and risk mitigation strategy selection is a medium range tactical level planning problem (Cheaitou and Khan, 2015). Thus, we consider a one year planning model with weekly demand and supply replenishment. We develop a multi-period stochastic optimization problem 
with fifty-two periods by utilizing multi-objective mixed integer programming (MOMIP), which is a suitable approach for considering conflicting objectives.

We assume that the focal company produces one type of product. Without loss of generality, we further assume that the focal company requires one unit of raw material to produce one unit of finished product (Zimmer, 2002).

\subsection{Base model}

The problem is inherently a stochastic multi-stage decision problem in operating variables involving several sets of operating and structural constraints. Each decision stage corresponds to a planning period (denoted by $t$ ).

\section{- Decision variables}

$x_{i t} \quad$ order quantity from supplier $i$ in period $t$.

$Y_{t} \quad$ : quantity delivered to the customer in period $t$.

$z_{i}$ : binary variable that is 1 if supplier $i$ is selected, 0 otherwise.

$I_{t}$ : focal company's ending inventory level in period $t$.

$S_{t}$ : amount of shortage in period $t$.

$O_{t}$ : over-delivered amount in period $t$.

\section{- Parameters}

$c_{i} \quad$ : unit purchasing price for supplier $i$.

$f_{i} \quad$ : fixed cost for supplier $i$.

$h$ : unit inventory holding cost.

$p \quad$ : unit penalty cost for shortage.

$l \quad$ : unit transportation cost.

$C A_{i}$ : capacity of supplier $i$.

$C A_{f}$ : capacity of focal company.

$M I_{i}:$ minimum order quantity of supplier $i$. 
$\alpha_{i}$ : volume flexibility parameter for supplier $i, 0 \leq \alpha_{i} \leq 1$

$D_{t}$ : random demand in period $t$ with distribution parameter $\theta_{t}$.

IL : inventory lower bound (safety stock level of the focal company).

$I U$ : inventory upper bound (inventory holding capacity of the focal company).

$N \quad$ : number of supplier(s) utilized.

$r_{i} \quad$ : reliability score of supplier $i$.

$r_{f}$ : relative reliability of focal company.

- Objective Functions:

$$
\begin{aligned}
& \min \sum_{i}\left(c_{i} x_{i 1}+f_{i} z_{i}\right)+\mathrm{E}_{\theta_{1}}\left[\min \left(h I_{1}+l\left(Y_{1}+O_{1}\right)+p S_{1}\right)+\sum_{i} c_{i} x_{i 2}\right. \\
&+ \mathrm{E}_{\theta_{2}}\left[\min \left(h I_{2}+l\left(Y_{2}+O_{2}\right)+p S_{2}\right)+\sum_{i} c_{i} x_{i 3}\right. \\
&\left.\left.+\mathrm{E}_{\theta_{3}}\left[+\mathrm{E}_{\theta_{T}}\left[\min \left(h I_{T}+l\left(Y_{T}+O_{T}\right)+p S_{T}\right)\right]\right]\right]\right] \\
& \max \sum_{i} r_{i} x_{i 1}+\mathrm{E}_{\theta_{1}}\left[\max r_{f}\left(I_{1}+Y_{1}\right)+\sum_{i} r_{i} x_{i 2}\right. \\
&\left.+\mathrm{E}_{\theta_{2}}\left[\max r_{f}\left(I_{2}+Y_{2}\right)+\sum_{i} r_{i} x_{i 3}+\mathrm{E}_{\theta_{3}}\left[+\mathrm{E}_{\theta_{T}}\left[\max r_{f} Y_{T}\right]\right]\right]\right]
\end{aligned}
$$

Subject to

$$
\begin{array}{ll}
x_{i t} \leq C A_{i} z_{i} & \text { for } \forall i \text { and } t \\
x_{i t} \geq M I_{i} z_{i} & \text { for } \forall i \text { and } t \\
\left(1-\alpha_{i}\right) x_{i t-1} \leq x_{i t} \leq\left(1+\alpha_{i}\right) x_{i t-1} & \text { for } \forall i \text { and } t \\
I_{t}=I_{t-1}-Y_{t}+\sum_{i} x_{i t} & \text { for } \forall t>0, I_{0}=0 \\
I L \leq I_{t} \leq I U & \text { for } \forall t<T, I_{T} \text { can be less than } I L \\
I_{t-1}+\sum_{i} x_{i t}-Y_{t} \leq I U & \text { for } \forall t \\
Y_{t} \leq C A_{f} &
\end{array}
$$




$$
\begin{array}{ll}
S_{t} \geq D_{t}-Y_{t} & \text { for } \forall t \\
O_{t} \geq Y_{t}-D_{t} & \text { for } \forall t \\
\sum_{i} z_{i}=N & \\
x_{i t}, Y_{t}, I_{t}, S_{t}, O_{t} \geq 0 \text { and integer and } z_{i} \text { is binary } & \text { for } \forall i \text { and } t
\end{array}
$$

The first term in cost objective function, Eq. (1), is sourcing cost in the first planning period. The second term is a fixed cost for the selected supplier $i$. The last term represents the total cost of the $T$-stage decisions (involving the wait-and-see inventory, delivered/over delivered, and shortage variables) at each planning period and the here-and-now sourcing variables of the adjacent planning period. Similarly, in the reliability objective function, Eq. (2), the first term represents reliability from sourcing in the initial period. The second term represents the total reliability of the $T$-stage decisions (involving the variables for wait-and-see inventory and customer delivery amount) at each planning period and the here-and-now sourcing variables of the adjacent planning period. For the last period, i.e., period $T$, inventory is of no use, thus it is not included in the calculation of total reliability of the focal company. Note that total reliability objective depends on the reliability of the focal company as well as the amount sourced from the suppliers, inventory amount carried, and delivery amount to the customers. We utilize the relative scores obtained using AHP (values between 0 and 1) based on the data used in Kull and Talluri (2008) for the unit reliability scores of the suppliers. Thus, sourcing larger quantities from a more reliable supplier will increase total reliability.

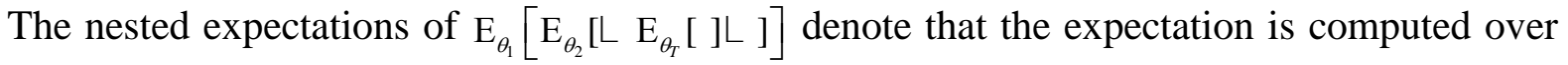
the probability distribution of the cumulative demand $D_{t}$ with parameter set $\theta_{t}$ up to each plan- 
ning period $t$, where the inner expectation is conditioned on the realization of the uncertain demand of the outer expectation. Thus, the sourcing variables, $x_{i t}$ are determined after the demand requirements up to period $t-1$ have been realized but before the demand outcomes for period $t$ and subsequent periods are known. Consequently, the decision on the sourcing variables for period $t$ should take into account the state at the beginning of planning period $t$ and the possible demand outcomes in later periods. This is formalized through constraint (6), which links the decisions of two adjacent planning periods. The supply variables $Y_{t}$ take into account the demand outcomes for planning period $t$ and serve to constrain the state variables $I_{t}, O_{t}$, and $S_{t}$.

The constraints, Eqs. (3) - (12), are generated for each demand sample path (scenario) at each planning period in the deterministic equivalent formulation. Eq. (3) limits sourcing amount up to each supplier's capacity. Eq. (4) constrains the minimum sourcing amount for suppliers. Eq. (5) sets upper and lower bounds of sourcing amount based on the volume flexibility offered by suppliers. Eq. (6) is a typical inventory balance equation between adjacent periods. Note that $I_{t}$ is determined based on demand realization up to planning period $t$. Eq. (7) sets an upper bound for inventory level due to inventory carrying capacity of the focal company and a lower bound for inventory level due to the safety stock set by the focal company. Eq. (8) constrains the focal company's production capacity. Eq. (9) limits focal company's delivery amount to the customer. Eq. (10) and (11) represent shortage and over delivery constraints, respectively. Eq. (12) restricts the number of selected suppliers.

If the demand distribution was a discrete function, the evolution of random demands over time can be represented by the tree structure. However, the total number of scenarios will be extremely large. For example, if there are $\Sigma$ possible next-period demand realizations at each node, the total number of scenarios over $T$ periods is $\Sigma^{T}$. Thus, for computational efficiency, we employ an 
approximation strategy through simulation (Jung et al., 2004) rather than applying discrete time Markov decision processes using a dynamic programming approach.

\subsection{Base MOMIP with deterministic model}

Deterministic models are developed for their execution within the simulation. The models are derived from the original stochastic program formulation developed in the previous section. In addition, the deterministic models are transformed to the MOMIP so that it can address cost and reliability simultaneously.

\section{- Deterministic Objective Functions:}

$$
\begin{aligned}
& \min \sum_{i}\left(f_{i} z_{i}+\sum_{t} c_{i} x_{i t}\right)+\sum_{t}\left[h I_{t}+l\left(Y_{t}+O_{t}\right)+p S_{t}\right] \\
& \max \sum_{i} \sum_{t} r_{i} x_{i t}+\sum_{t}\left[r_{f}\left(I_{t}+Y_{t}\right)\right]-r_{f} I_{T}
\end{aligned}
$$

Subject to

Eqs. (3) - (9) and Eqs. (12) - (13)

$$
\begin{array}{ll}
S_{t} \geq \mathrm{E}\left[D_{t}\right]-Y_{t} & \text { for } \forall t \\
O_{t} \geq Y_{t}-\mathrm{E}\left[D_{t}\right] & \text { for } \forall t
\end{array}
$$

The first term of Eq. (14) represents total procurement cost over the planning horizon. The second term of Eq. (14) represents total inventory carrying, delivery, and penalty costs. The last term of Eq. (14) is the fixed cost for supplier selection. Similarly, the first term of Eq. (15) represents total reliability from sourcing over the planning horizon. The second term of Eq. (15) implies total reliability from inventory and delivery to the customer over the planning horizon. The last term of Eq. (15) implies deduction of reliability of last period's inventory. Intuitively, lower cost and higher reliability are better. Thus, cost objective function, Eq. (14), needs to be minimized but reliability objective function, Eq. (15), needs to be maximized. Most of the constraints used in the 
base model (the model described in section 4.1) are maintained, but Eqs. (10) and (11) are modified by applying expected demand, E[ $\left.D_{t}\right]$, instead of stochastic demand, $D_{t}$, for the purpose of running the simulation. The details of simulation are discussed in Section 5.

As noted earlier, the problem we are considering is a multi-objective optimization problem with two conflicting objective functions. We try to balance the two objectives using a min-max strategy to obtain near Pareto optimal solutions. The min-max strategy compares relative deviations from the separately attainable optimum solutions by solving the optimization problems for each objective separately, i.e., solve the optimization problem with all constraints for Eq. (14) and Eq. (15) separately in order to derive the best possible cost (lowest cost) and best possible reliability (highest reliability). Once we have the best possible values, the two models are combined as one MOMIP with three additional variables and two additional constraints. We use the following master formulation to perform this:

\section{- Deterministic MOMIP for base model:}

$$
\min Q
$$

Subject to

Eqs. (3) - (9), Eqs. (12) - (13), and Eqs. (16) - (17)

$$
\begin{aligned}
& -\frac{\omega_{R}(R K-B R)}{B R} \leq Q \\
& \frac{\omega_{C}(C S-B C)}{B C} \leq Q
\end{aligned}
$$

, where $Q$ is a variable to balance the two objectives, $Q \geq 0$. We utilize a min-max approach that minimizes maximum deviations from both objective functions values when (14) and (15) are optimized in isolation, based on the given set of weights for cost and reliability, $\left(\omega_{C}, \omega_{R}\right)$. Note that constraints Eqs. (10) - (11) are replaced by Eqs. (16) - (17) because of the transformation from 
stochastic to deterministic approach. Moreover, we have two additional decision variables and four additional parameters as follows.

\section{- Additional decision variables}

$C S$ : total cost function value, i.e., $C S=\sum_{i}\left(f_{i} z_{i}+\sum_{t} c_{i} x_{i t}\right)+\sum_{i} \sum_{t}\left[h I_{t}+l\left(Y_{t}+O_{t}\right)+p S_{t}\right]$

$R K$ : total reliability function value, i.e., $R K=\sum_{i} \sum_{t} r_{i} x_{i t}+\sum_{t}\left[r_{i}\left(I_{t}+Y_{t}\right)\right]-r_{f} I_{T}$

\section{- Additional parameters}

$\omega_{C}:$ weight for cost.

$\omega_{R}$ : weight for reliability.

$B C$ : cost achieved when cost objective function (Eq. (14)) is optimized in isolation

$B R$ : reliability achieved when reliability objective function (Eq. (15)) is optimized in isolation

Note that the weights project the risk attitude of a focal company's focus; the higher (lower) $\omega_{C}$ compared to $\omega_{R}$, the more cost focused the company is. The changes in the weights enable us to perform the Pareto analysis.

\subsection{Models for sole strategy selection}

We expect that the Pareto analysis might have a monotone increasing shaped curve, i.e., total reliability is increasing in total cost, i.e., as $\omega_{R} / \omega_{C}$ increases the curves move from the lower left to the upper right (see Figure 2). However, each risk mitigation strategy has its own parameter set, which implies that each strategy's $B C$ and $B R$ will be different. Thus, comparing $Q$ values of the strategies at a certain weight combination, $\omega_{C}$ and $\omega_{R}$, is not meaningful. Thus, separately estimating cost/reliability curves of the strategies first, and then comparing them at a certain total cost or total reliability level will derive more meaningful results. 
As can be seen in Figure 2, at a given total cost level, the grey curve shows better performance compared to the black curve on the left side of the break-even cost line (the vertical dotted-line), while the black curve performs better on the right side, since higher reliability level can be achieved with the same cost. Each risk mitigation strategy's curve (sole strategy) can be separately drawn by the following models.

\section{Insert Figure 2 Here}

Based on the supplier(s) selected in the base MOMIP, i.e., $z_{i}^{*}$ 's become parameters in strategy selection, we modify Eq. (1) - (20) with several additional decision variables and parameters and related constraints. Script $\kappa$ denotes risk mitigation strategy, i.e., $\kappa \in\{$ ARS, HFS, IC, IV $\}$.

\section{- Deterministic MOMIP for each strategy $\kappa$ :}

$\min Q^{\kappa}$

Subject to

Eqs. (3) - (9), Eqs. (12) - (13), Eqs. (16) - (17), and Eq. (19) - (20) with addition of superscript $\kappa$ on all decision variables and some of focal company's parameters.

In addition, objective functions, Eqs. (14) - (15) and their objective function values at optimal solution $B C^{\kappa}$ and $B R^{\kappa}$ need to be recalculated based on the revised set of parameters for strategy $\kappa$. To solve MOMIP for each strategy, several additional constraints are required. The modifications and additions are summarized in Table 3.

Insert Table 3 Here

\subsection{Models for simultaneous selection for strategies}

Using the aforementioned individual strategies, we define four different combinations of upstream and downstream risk mitigation strategies; ARS+IC, ARS+IV, HFS+IC, and HFS+IV. There could be other combinations such as IC+IV, ARS+HFS, ARS+HFS+IC+IV, etc. in practice, but 
we focus on the first four combinations to simplify the model. Similar to the sole strategy selection, the models are modified based on the MOMIP of base model. Each model takes upstream strategy's supplier related constraints, while taking downstream strategy's modified parameters. For example, the combination of ARS+IC can have ARS's modified and additional constraints rather

than having IC's additional constraint appeared in Table 3, i.e., $\sum_{i} z_{i}^{\mathrm{ARS}+\mathrm{IC}}=N^{\mathrm{ARS}}=N^{\mathrm{ARS}+\mathrm{IC}}$ and $z_{i}^{\mathrm{ARS}+\mathrm{IC}} \geq z_{i}^{*}$. However, this combination will apply the modified focal company's capacity, i.e., $C A_{f}^{\mathrm{ARS}+\mathrm{IC}}=C A_{f}^{\mathrm{IC}}$, since ARS does not increase focal company's production capacity. Moreover, the investment costs are the same as the downstream risk mitigation strategies' investment costs, i.e., $I S^{\mathrm{ARS}+\mathrm{IC}}=I S^{\mathrm{IC}}$ because investment cost for ARS is accounted by fixed cost in Eq. (20) and there is no additional investment cost other than the fixed cost for the selection.

\section{Numerical Experiments and Results}

The models (including base, sole strategy selection, and simultaneous selection of strategies) are initially solved with deterministic MOMIP under expected demand. Then, the repeated simulation of the supply chain operations will be applied based on the initial solutions over the planning horizon, each with a given Monte-Carlo sample of demands. Within each simulation, a series of planning problems are solved under the rolling horizon scheme and solutions are updated. The following summarizes the procedure.

Step 0: run the deterministic base MOMIP with given state (based on the forecasted demand) to obtain the sourcing decision $x_{i t}$ for period $t$ (at $\left.t=1\right)$.

Step 1: run the discrete event simulation with demand outcomes (realized demand from the MonteCarlo sampling) for the planning period $t$, i.e., revise $Y_{t}, S_{t}, O_{t}$, and $I_{t}$. Note that the demand outcomes are recorded for future steps. 
Step 2: update and record $I_{t}$ at the end of planning period $t$ and parameterize $z_{i}$ 's, i.e., set $z_{i}=z_{i}^{*}$.

Step 3: set $t=t+1$ and go to step 0 until $t=T$.

Step 4: set $t=1$ and initialize $z_{i}^{\kappa}=z_{i}^{*}$.

Step 5: separately run the deterministic MOMIP models (including four sole strategies and four simultaneous selection of strategies) with given state (based on the recorded forecasted demand at Step 1) to obtain the sourcing decision $x_{i t}^{\kappa}$ for period $t$.

Step 6: separately run the discrete event simulations for all eight models with demand outcomes (recorded at Step 1) for the planning period $t$, i.e., revise $Y_{t}^{\kappa}, S_{t}^{\kappa}, O_{t}^{\kappa}$, and $I_{t}^{\kappa}$.

Step 7: update and record $I_{t}^{\kappa}$ at the end of planning period $t$ and parameterize $z_{i}^{\kappa}$,s, i.e., fix $z_{i}^{\kappa}=z_{i}^{\kappa^{*}}$

Step 8: set $t=t+1$ and go to step 5 until $t=T$.

By repeating the above procedure for sufficient number times ${ }^{2}$, we measure the performance of each individual mitigation strategy as well as each combined strategy. We run the models with the input parameters used in Kull and Talluri (2008) including information related to suppliers, focal company and customer demand. For investment cost, $I S^{\mathrm{IC}}$ and $I S^{\mathrm{IV}}$, we employ the estimation approach used in Talluri et al. (2013), where data from the United States Census Bureau and from CAPS Research (a global research center for strategic supply management) are summarized by NAICS code to utilize a range of typical costs with respect to the value of total capacity. Investment costs are calculated by using industrial annual cost estimates. These figures are then scaled to the size of our simulated company. For more details, we refer the reader to Talluri et al.

\footnotetext{
${ }^{2}$ To determine the number of replications, we employ a simple graphical approach suggested by Robinson (2014), which suggests that as more replications are performed the cumulative mean of output should show minimal variability and there should be no upward or downward trend. Our results show that after $20^{\text {th }}$ replication, the cumulative means are very stable.
} 
(2013). Table 4 indicates all the parameters used in the analysis with corresponding sources and assumptions.

By applying Monte-Carlo sampling approach, we generate one hundred sets of normally distributed synthetic demand data. Similar to Toktay and Wein (2001) and Dobos and Richter (2004), we assume stationary demand $D_{t}$ over planning horizon (52 weeks), i.e., $\theta_{1}=\theta_{2}=\theta_{52}$ with $\mu_{D}=2,000,000 / 52$ and $\sigma_{D}^{2}=0.2 \cdot \mu_{D}$. Based on the demand data and simulation model, we initially run the base MOMIP model (reference model).

\section{Insert Table 4 Here}

In order to consider a variety of cost versus reliability trade-offs from the focal company's standpoint, we run the model over various weight sets (Table 5). The results show that total reliability is increasing with a decreasing rate in total cost, i.e., a concave shaped curve. This result is consistent to the findings in (Yildiz et al., 2015). Figure 3.1 depicts the averaged result of the 100 different demand sets, and Figure 3.2 is the averaged sourcing allocation based on the 100 demand sets.

\section{Insert Figure 3.1 and 3.2 Here}

Insert Table 5 Here

When we compare the "Cost Only" and "Set 1" solutions in Figure 3.1, we see that a large improvement in reliability is achieved with a relatively low increase in total cost. However, when we look at the other subsequent solutions in the same graph (Set 2, Set $3, \ldots$ Rel. Only), we see that the gains in reliability decrease as reliability is emphasized more and cost is emphasized less (the slope of the curve is decreasing as the ratio of $\omega_{C}$ to $\omega_{R}$ decreases). Figure 3.2 presents the suppliers selected and the amount sourced from them over the planning horizon for three different sets of cost \& reliability weight sets for the base model. These sets include Set 1 (in blue), which 
emphasizes cost, Set 5 (in black), which is neutral in its emphasis on cost and reliability, and Set 9 (in red), which emphasizes reliability. This graph and similar other graphs (Figures 4.3, 4.4, 4.5, 4.6, 5.3, 5.4, 6.3, 6.4, 7.3, 7.4) are referred as "Supplier selection and allocation" graphs in the rest of the paper. This graph shows that the base model is constrained by single sourcing (only Supplier A is selected over different sets of weights. Nothing is sourced from the other two suppliers), which means that this model reduces risk (increase reliability) only through changing sourcing amount, delivery amount to the customer, and inventory level. The next set of figures shows the effects of individual risk mitigation strategies.

\section{Insert Figure 4.1 and 4.2 Here \\ Insert Figure 4.3 and 4.4 Here \\ Insert Figure 4.5 and 4.6 Here}

With the parameter set and the synthetic demand data used, upstream risk mitigation strategies (ARS and HFS) do not seem to result in much improvement over the reference results when no mitigation strategy is used (Figure 4.1), while downstream risk mitigation strategies (IC and IV) improve the focal company's performance in both cost and reliability objectives (Figure 4.2). More specifically, when ARS is utilized, increased sourcing availability from dual sourcing from Suppliers A and B does not significantly increase focal company's performance, as seen in Figure 4.1, since sourcing amount is constrained by the focal company's manufacturing capacity. As shown in Figure 4.3, the focal company sources a higher amount (than its manufacturing capacity) from the selected suppliers in the earlier periods (weeks 1 and 2) because its inventory holding capacity can accommodate those extra amounts in these early periods. However, once the inventory holding capacity is fully utilized, the effect of increased sourcing availability disappears. In the case of HFS, we see that Figure 4.5 is almost identical to the order allocation graph of reference model in Figure 3.2. As clearly seen in Figure 4.1, HFS does not significantly change the performance curve 
compared to the reference model, either. The only meaningful difference is shown at Cost Only weight set solution (left extreme point of the curves). This is because, in the reference model, the focal company does not select Supplier A, since it is more expensive than the other two suppliers. However, HFS strategy forces the focal company to select Supplier A, which creates the difference we observe.

In Figure 4.2, we can initially confirm our first conjecture that the best strategy can vary depending on focal company's focus on cost vs reliability, i.e., cost focused company versus reliability focused company. The IC is a better strategy when the focal company is cost focused. However, IV becomes the better strategy when the focal company is reliability focused. This can be explained by the tight production capacity of the focal company. The increased manufacturing capacity (IC) enables the focal company reduce lost sales and increase demand satisfaction. As shown in Figure 4.4, IC enables the focal company to source more amount from the selected supplier (Supplier A) over the planning periods compared to reference model at Sets 1 and 5 (blue and black curves respectively). This can reduce total cost and at the same time increase reliability, when focal company is not reliability focused. However, this positive effect is attenuated as the company becomes more reliability focused, since the focal company will source more quantity and deliver more quantity under this attitude even in the base (reference) case. As shown in Figure 4.4, the curve for Set 9 (red curve) is almost identical to the curve in Figure 3.2. This behavior in the reference model can be strengthened with IV so that the performance can be increased for a high reliability focused company. As shown in Figure 4.6, the allocations under IV are similar to those under the reference model, as seen in Figure 3.2. However, increased inventory capacity enables the focal company carry more inventory so that the performance curve can be improved, while the overall shape of performance curve is maintained. 
Insert Figure 5.1 and 5.2 Here

Insert Figure 5.3 and 5.4 Here

In terms of combined vs individual strategies, Figure 5.1 shows that the combined strategy (ARS+IC) results in superior performance compared to the individual strategies (ARS only and IC only). This result can be interpreted as an indicator of the importance of alignment between the individual strategies in a combined strategy in the following way: Since the capacity of the focal company is tight (i.e., expected demand is equal to capacity), the capacity increase (IC) enables the focal company to enjoy the increased sourcing availability achieved from the dual sourcing (ARS). Figure 5.3 shows that the focal company might want to utilize Supplier A (reliable supplier) more than Supplier B (cheaper supplier) as emphasis on reliability increases. Different from the order allocation under ARS only, the focal company still utilizes Supplier A more than Supplier B, i.e. sourcing amount from Supplier A is greater than that from Supplier B, over most periods when using weight Set 5 (black curve) under ARS + IC. In Figure 5.2, the combined strategy does not result in a similar improvement over the sole strategies since there is not an alignment between these strategies: With the increased inventory capacity (IV) and increased sourcing availability (ARS), although the focal company can store more inventory, it cannot increase its delivery of finished products at the same level due to constrained manufacturing capacity, which limits its ability to increase total reliability. As shown in Figure 5.4 We can observe that the allocation under ARS + IV is similar to that of under ARS (Figure 4.3).

Insert Figure 6.1 and 6.2 Here

Insert Figure 6.3 and 6.4 Here

Similar results are obtained in Figures 6.1 and 6.2, which show that the combinations of HFS and downstream risk mitigation strategies (IC or IV) do not improve the risk mitigation performance compared to the better performance achieved among the sole strategies. In other words, the 
combination of HFS and IC does not significantly outperform IC only strategy (the better strategy among HFS only and IC only). The increased focal company capacity (IC) increases the total reliability by increasing delivery amount to the customer and avoiding shortage costs. To achieve this effect, the focal company should source some redundant amount from the selected supplier. However, as we noticed in the supplier selection and allocation graph in Figure 3, Supplier A is already selected in the reference model. Thus, HFS might not improve the performance of IC only. As we can expect, the allocation graph for HFS + IC shown in Figure 6.3 is the same as the allocation graph of IC shown in Figure 4.4. IV mitigates risk by increasing inventory capacity level. Thus, this strategy leads the focal company to source some redundant amount from the supplier. However, because of the same reason (Supplier A is selected in the reference model) HFS does not significantly increase the efficiency of the use of IV only and the allocation in Figure 6.4 is the same as that in Figure 4.6.

As shown in all the order allocation graphs, we can observe that capacity tightness (i.e., weekly capacity being equal to expected weekly demand) plays a critical role. The capacity tightness increases focal company's manufacturing capacity utilization, which in turn highly increases supplier's capacity utilization even when Set 1 is used, which emphasizes cost over reliability. Because of that, we also test our models with a lower demand, i.e., $\mu_{D}=1,500,000 / 52=75 \%$ of focal company's manufacturing capacity while maintaining the other parameter values.

Insert Figure 7.1 and 7.2 Here

Insert Figure 7.3 and 7.4 Here

As we can expect, the positive effect of IC disappears (see Figure 7.1) in this scenario. As shown in Figures 7.2 and 7.3, the increased manufacturing capacity will not be used if the emphasis on reliability is not very high so that selected suppliers' (Supplier A at Set 5 and Supplier B at Set 1) capacity will not be fully utilized. Thus, very similar performance and sourcing behavior are 
observed at Sets 1 and 5. On the other hand, when the emphasis on reliability becomes very high, the focal company tries to increase total reliability by sending more units to its customer, which increases the utilization of selected supplier's (Supplier A) capacity. This behavior extends to right tail of the performance curve, but does not improve focal company's performance as shown in Figure 7.1. However, as we observed in the results under the initial parameter set, IV maintains similar sourcing behavior, i.e., Figure 7.4 is similar to Figure 7.2, but it improves focal company's performance under lower demand. Note that ARS, HFS, ARS+IC and HFS+IC do not significantly result in a performance improvement over the reference model and ARS+IV and HFS+IV do not significantly improve the performance curve of IV only.

We also conduct a sensitivity analysis on some key supplier parameters (unit price and reliability), as shown in Table 6. In the original parameter set, Supplier A excels in flexibility and reliability, but its unit price is slightly more expensive than the other suppliers. Moreover, there is no price difference between Supplier B and C.

Insert Table 6 Here

Insert Figure 8.1 and 8.2 Here

Insert Figure 8.3 and 8.4 Here

Insert Figure 8.5 and 8.6 Here

As shown in Figures 8.1 - 8.6, overall effectiveness of each mitigation strategy is maintained (compared to the results under original parameter set with higher demand). Upstream strategies including ARS and HFS do not significantly improve focal company's performance, while downstream strategies provide significant improvement. IC (IV) will be preferred when the emphasis on cost (reliability) is higher than reliability (cost). Moreover, the combination of ARS and IC outperforms other strategies.

Interestingly, we notice that HFS makes a large deviation from the reference model (Figures 8.1, 8.5 and 8.6). As shown in Table 6, Supplier A (most flexible supplier) is very expensive than 
the other two suppliers. Thus, HFS is not an attractive strategy when emphasis on reliability is not high enough. Moreover, Supplier A is selected in reference model when the weight for reliability is high, which implies that the performance curve of reference model and HFS converges as weight for reliability increases.

\section{Conclusions and Extensions}

In this study, using multi-objective optimization and analysis, we show that different risk mitigation strategies suit better to firms with different preferences on cost and reliability trade-off, i.e. focus on cost versus reliability. Moreover, we simultaneously address the issue of supplier selection with risk mitigation strategy selection. We argue that risk mitigation should be considered at the supplier selection phase with the combination of upstream and downstream risk mitigation strategies rather than separately applying a sole strategy. The results show that the simultaneous consideration of upstream and downstream risk mitigation strategies has the potential for better performance than using each strategy solely. However, the combined strategies do not guarantee that they outperform sole strategies, which means that the alignment between the strategies in a combination is critical for better performance.

Moreover, demand - capacity relationship influences the effectiveness of risk mitigation strategies. More specifically, if capacity is not tight, i.e., the focal company's manufacturing capacity and selected suppliers' capacity are high enough (compared to demand), most sole strategies do not significantly improve the focal company's performance. In our analysis, IV is the only strategy that can significantly improve focal company's performance, which implies that inventories can effectively manage risks rather than increasing sourcing availability (ARS), increasing sourcing

flexibility (HFS), and/or increasing manufacturing capacity (IC). Thus, we can expect that none of the combinations of these individual strategies would significantly outperform IV in this case. 
Our analysis shows that focal company's sourcing patterns under reference model are maintained even after IV is applied, which are observed not only in the original scenario but also in both the lower demand scenario and modified supplier parameter scenario. Thus, IV can be a base strategy, since it always improves focal company's performance, even though it might not be the best strategy. Moreover, IC is preferred when the emphasis on cost is relatively high, while IV is preferred when the emphasis on reliability is relatively high (given that capacity is tight). Note that the effectiveness of IC disappears when focal company's manufacturing capacity is high enough, since focal company will not fully utilize its manufacturing capacity when the emphasis on cost is relatively high and in turn, increasing sourcing availability achieved by ARS will not be an effective strategy. Thus, none of the combinations considered in this paper significantly improve focal company's performance compared to the performance under IV only when capacity is not tight. Therefore, we can conclude that risk mitigation strategies become more effective when risk level is high, i.e., focal company's capacity is tight. This is similar to an appropriate treatment becoming effective on patients who show a certain symptom. Just like the possibility of simultaneous treatment options being more effective on patients, the potential for the well aligned combined strategies also can be utilized for risk mitigation in supplier selection. As we discussed in Section 5, upstream strategies alone are not very attractive options. The preference on downstream strategies depends on the company's attitude (cost focused versus reliability focused), i.e., IC is preferred by cost focused, while IV is preferred by reliability focused at high risk level. Similar to the inexistence of a panacea, there is no one-size fit all risk mitigation strategy either. However, well aligned combinations might create synergy so that outperform sole strategies. Thus, we can conjecture that downstream strategies could be foundations (mainstream treatment) and upstream strategies could 
be editions (adjuvant treatment), i.e., ARS+IC becomes the best combined strategy at tight capacity with stable demand.

There are some limitations of our study. First, we consider only four different risk mitigation strategies including two upstream and two downstream strategies because of space limits. However, there are other risk mitigation strategies developed in literature. Therefore, an extension of this study could investigate more effective combined strategies by considering combinations of other mitigation strategies. More specifically, our model addressed demand uncertainty as the only downstream risk. However, by including multiple customers (rather than a single customer), the model can abstract a more realistic environment that can incorporate customer's reliability, which enables us to test other downstream strategies such as having more customer accounts as suggested by Chopra and Sodhi (2007).

Second, we only consider the combinations composed of one upstream and one downstream mitigation strategy for simplicity. However, more than one upstream and downstream strategies can also be combined (such as ARS+IC+IV) as many companies employ in practice. Lastly, even though we consider a stationary demand set over 52-week time horizon, applying the model with various demand patterns such as seasonal demand and inverted U-shape demand (product life cycle) will provide the decision makers with more sophisticated analysis that fit various situations.

\section{References}

Amid, A., S. Ghodsypour and C. O'Brien. 2011. "A weighted max-min model for fuzzy multiobjective supplier selection in a supply chain." International Journal of Production Economics 131(1): 139-145.

Aqlan, F. and S. S. Lam. 2015. "A fuzzy-based integrated framework for supply chain risk assessment." International Journal of Production Economics 161: 54-63.

Chan, F. T. and N. Kumar. 2007. "Global supplier development considering risk factors using fuzzy extended AHP-based approach." Omega 35(4): 417-431. 
Chaudhuri, A., B. K. Mohanty and K. N. Singh. 2013. "Supply chain risk assessment during new product development: a group decision making approach using numeric and linguistic data." International Journal of Production Research 51(10): 2790-2804.

Cheaitou, A. and S. A. Khan. 2015. "An integrated supplier selection and procurement planning model using product predesign and operational criteria." International Journal on Interactive Design and Manufacturing 9(3): 213-224.

Chen, P.-S. and M.-T. Wu. 2013. "A modified failure mode and effects analysis method for supplier selection problems in the supply chain risk environment: A case study." Computers \& Industrial Engineering 66(4): 634-642.

Choi, T. Y. and D. R. Krause. 2006. "The supply base and its complexity: Implications for transaction costs, risks, responsiveness, and innovation." Journal of Operations Management 24(5): 637-652.

Chopra, S., G. Reinhardt and U. Mohan. 2007. "The importance of decoupling recurrent and disruption risks in a supply chain." Naval Research Logistics 54(5): 544-555.

Chopra, S. and M. S. Sodhi. 2004. "Managing risk to avoid supply-chain breakdown." MIT Sloan management review 46(1): 53.

Chopra, S. and M. S. Sodhi. 2014. "Reducing the risk of supply chain disruptions." MIT Sloan Management Review 55(3): 73.

Dey, P. K., A. Bhattacharya and W. Ho. 2015. "Strategic supplier performance evaluation: A casebased action research of a UK manufacturing organisation." International Journal of Production Economics 166: 192-214.

Dobos, I. and K. Richter. 2004. "An extended production/recycling model with stationary demand and return rates." International Journal of Production Economics 90(3): 311-323.

Fahimnia, B., C. S. Tang, H. Davarzani and J. Sarkis. 2015. "Quantitative models for managing supply chain risks: A review." European Journal of Operational Research 247(1): 1-15.

Fang, C., X. Liao and M. Xie. 2016. " A hybrid risks-informed approach for the selection of supplier portfolio." International Journal of Production Research 54(7): 2019-2034.

Gaudenzi, B. and A. Borghesi. 2006. "Managing risks in the supply chain using the AHP method." The International Journal of Logistics Management 17(1): 114-136.

Ghodsypour, S. H. and C. O’brien. 2001. "The total cost of logistics in supplier selection, under conditions of multiple sourcing, multiple criteria and capacity constraint." International journal of production economics 73(1): 15-27. 
Giunipero, L. C. and R. Aly Eltantawy. 2004. "Securing the upstream supply chain: a risk management approach." International Journal of Physical Distribution \& Logistics Management 34(9): 698-713.

Goffin, K., F. Lemke and M. Szwejczewski. 2006. "An exploratory study of 'close' suppliermanufacturer relationships." Journal of operations management 24(2): 189-209.

Gonzalez, M. E., G. Quesada and C. A. Mora Monge. 2004. "Determining the importance of the supplier selection process in manufacturing: a case study." International Journal of Physical Distribution \& Logistics Management 34(6): 492-504.

Hallikas, J., I. Karvonen, U. Pulkkinen, V.-M. Virolainen and M. Tuominen. 2004. "Risk management processes in supplier networks." International Journal of Production Economics 90(1): 47-58.

Hallikas, J., K. Puumalainen, T. Vesterinen and V.-M. Virolainen. 2005. "Risk-based classification of supplier relationships." Journal of Purchasing and Supply Management 11(2): 72-82.

Hauer, L. M. 2003. "Risk-adjusted supply chain management." SUPPLY CHAIN MANAGEMENT REVIEW 7(6): 64-71.

Heckmann, I., T. Comes and S. Nickel. 2015. "A critical review on supply chain risk-Definition, measure and modeling." Omega 52: 119-132.

Hendricks, K. B. and V. R. Singhal. 2005. "An empirical analysis of the effect of supply chain disruptions on long-run stock price performance and equity risk of the firm." Production and Operations management 14(1): 35-52.

Ho, W., T. Zheng, H. Yildiz and S. Talluri. 2015. "Supply chain risk management: a literature review." International Journal of Production Research 53(16): 5031-5069.

Jung, J. Y., G. Blau, J. F. Pekny, G. V. Reklaitis and D. Eversdyk. 2004. "A simulation based optimization approach to supply chain management under demand uncertainty." Computers \& chemical engineering 28(10): 2087-2106.

Jüttner, U., H. Peck and M. Christopher. 2003. "Supply chain risk management: outlining an agenda for future research." International Journal of Logistics: Research and Applications 6(4): 197-210.

Kleindorfer, P. R. and G. H. Saad. 2005. "Managing disruption risks in supply chains." Production and operations management 14(1): 53-68.

Kull, T. J. and S. Talluri. 2008. "A supply risk reduction model using integrated multicriteria decision making." IEEE Transactions on Engineering Management 55(3): 409-419. 
Kumar, M., P. Vrat and R. Shankar. 2006. "A fuzzy programming approach for vendor selection problem in a supply chain." International Journal of Production Economics 101(2): 273285.

Lin, R.-H. 2012. "An integrated model for supplier selection under a fuzzy situation." International Journal of Production Economics 138(1): 55-61.

Lockamy III, A. and K. McCormack. 2010. "Analysing risks in supply networks to facilitate outsourcing decisions." International Journal of Production Research 48(2): 593-611.

Meena, P., S. Sarmah and A. Sarkar. 2011. "Sourcing decisions under risks of catastrophic event disruptions." Transportation research part E: logistics and transportation review 47(6): 1058-1074.

Miller, K. D. 1992. "A framework for integrated risk management in international business." Journal of international business studies 23(2): 311-331.

Moghaddam, K. S. 2015. "Supplier selection and order allocation in closed-loop supply chain systems using hybrid Monte Carlo simulation and goal programming." International Journal of Production Research 53(20): 6320-6338.

Mohammaddust, F., S. Rezapour, R. Z. Farahani, M. Mofidfar and A. Hill. 2017. "Developing lean and responsive supply chains: A robust model for alternative risk mitigation strategies in supply chain designs." International Journal of Production Economics 183: 632-653.

Nishat Faisal, M., D. K. Banwet and R. Shankar. 2006. "Supply chain risk mitigation: modeling the enablers." Business Process Management Journal 12(4): 535-552.

Önüt, S., S. S. Kara and E. Işik. 2009. "Long term supplier selection using a combined fuzzy MCDM approach: A case study for a telecommunication company." Expert Systems with Applications 36(2): 3887-3895.

Rao, C., X. Xiao, M. Goh, J. Zheng and J. Wen. 2017. " Compound mechanism design of supplier selection based on multi-attribute auction and risk management of supply chain." Computers \& Industrial Engineering 105: 63-75.

Rao, S. and T. J. Goldsby. 2009. "Supply chain risks: a review and typology." The International Journal of Logistics Management 20(1): 97-123.

Ravindran, A. R., R. Ufuk Bilsel, V. Wadhwa and T. Yang. 2010. "Risk adjusted multicriteria supplier selection models with applications." International Journal of Production Research 48(2): 405-424.

Robinson, S. (2014). Simulation: the practice of model development and use. Palgrave Macmillan. 
Ruiz-Torres, A. J., F. Mahmoodi and A. Z. Zeng. 2013. "Supplier selection model with contingency planning for supplier failures." Computers \& Industrial Engineering 66(2): 374-382.

Sawik, T. 2014. "Joint supplier selection and scheduling of customer orders under disruption risks: Single vs. dual sourcing." Omega 43: 83-95.

Sarkis, J. and S. Talluri. 2002. "A model for strategic supplier selection." Journal of Supply Chain Management 38(4): 18-28.

Schmitt, A. J. 2011. "Strategies for customer service level protection under multi-echelon supply chain disruption risk." Transportation Research Part B: Methodological 45(8): 1266-1283.

Scott, J., W. Ho, P. K. Dey and S. Talluri. 2015. "A decision support system for supplier selection and order allocation in stochastic, multi-stakeholder and multi-criteria environments." International Journal of Production Economics 166: 226-237.

Scott, J. A., W. Ho and P. K. Dey. 2013. "Strategic sourcing in the UK bioenergy industry." International Journal of Production Economics 146(2): 478-490.

Smeltzer, L. R. and S. P. Siferd. 1998. "Proactive supply management: the management of risk." International Journal of Purchasing and Materials Management 34(4): 38-45.

Sodhi, M. S., B. G. Son and C. S. Tang. 2012. "Researchers' perspectives on supply chain risk management." Production and Operations Management 21(1): 1-13.

Spekman, R. E. 1988. "Strategic supplier selection: Understanding long-term buyer relationships." Business Horizons 31(4): 75-81.

Talluri, S. and R. Narasimhan. 2003. "Vendor evaluation with performance variability: A maxmin approach." European Journal of Operational Research 146(3): 543-552.

Talluri, S., R. Narasimhan and A. Nair. 2006. "Vendor performance with supply risk: A chanceconstrained DEA approach." International Journal of Production Economics 100(2): 212222.

Talluri, S. S., T. J. Kull, H. Yildiz and J. Yoon. 2013. "Assessing the efficiency of risk mitigation strategies in supply chains." Journal of Business Logistics 34(4): 253-269.

Tang, C. S. 2006. "Perspectives in supply chain risk management." International Journal of Production Economics 103(2): 451-488.

Tang, O. and S. N. Musa. 2011. "Identifying risk issues and research advancements in supply chain risk management." International Journal of Production Economics 133(1): 25-34.

Toktay, L. B. and L. M. Wein. 2001. "Analysis of a forecasting-production-inventory system with stationary demand." Management Science 47(9): 1268-1281. 
Tomlin, B. 2006. "On the value of mitigation and contingency strategies for managing supply chain disruption risks." Management Science 52(5): 639-657.

Viswanadham, N. and A. Samvedi. 2013. "Supplier selection based on supply chain ecosystem, performance and risk criteria." International Journal of Production Research 51(21): 6484-6498.

Wang, X., H. K. Chan, R. W. Yee and I. Diaz-Rainey. 2012. "A two-stage fuzzy-AHP model for risk assessment of implementing green initiatives in the fashion supply chain." International Journal of Production Economics 135(2): 595-606.

Wilding, R., B. Wagner, C. Colicchia and F. Strozzi. 2012. "Supply chain risk management: a new methodology for a systematic literature review." Supply Chain Management: An International Journal 17(4): 403-418.

Wu, D. D. and D. Olson. 2010. "Enterprise risk management: a DEA VaR approach in vendor selection." International Journal of Production Research 48(16): 4919-4932.

Wu, T., J. Blackhurst and V. Chidambaram. 2006. "A model for inbound supply risk analysis." Computers in Industry 57(4): 350-365.

Yildiz, H., S. DuHadway, R. Narasimhan and S. Narayanan. 2016. "Production Planning Using Evolving Demand Forecasts in the Automotive Industry." IEEE Transactions on Engineering Management 63(3): 296-304.

Yildiz, H., R. Ravi and W. Fairey. 2010. "Integrated optimization of customer and supplier logistics at Robert Bosch LLC." European Journal of Operational Research 207(1): 456-464.

Yildiz, H., J. Yoon, S. Talluri and W. Ho. 2015. "Reliable Supply Chain Network Design." Decision Sciences 47(4): 661-698.

Zimmer, K. 2002. "Supply chain coordination with uncertain just-in-time delivery." International Journal of Production Economics 77(1): 1-15.

Zsidisin, G. A. and L. M. Ellram. 2003. "An agency theory investigation of supply risk management." Journal of Supply Chain Management 39(2): 15-27.

Zsidisin, G. A., L. M. Ellram, J. R. Carter and J. L. Cavinato. 2004. "An analysis of supply risk assessment techniques." International Journal of Physical Distribution \& Logistics Management 34(5): 397-413.

Zsidisin, G. A. and M. E. Smith. 2005. "Managing supply risk with early supplier involvement: a case study and research propositions." Journal of Supply Chain Management 41(4): 44-57. 
Zsidisin, G. A., S. A. Melnyk and G. L. Ragatz. 2005. "An institutional theory perspective of business continuity planning for purchasing and supply management." International Journal of Production Research 43(16): 3401-3420. 


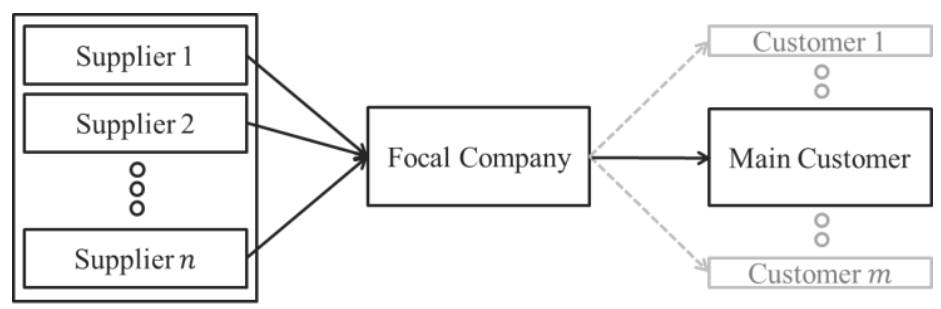

$\longrightarrow$ Physical Flow of raw materials and finished goods

Figure 1 Three-tier supply chain setting

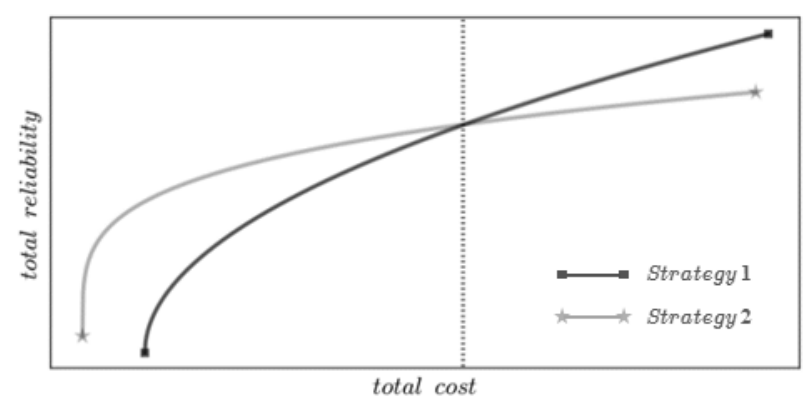

Figure 2 Depiction of anticipated comparison between two different strategies

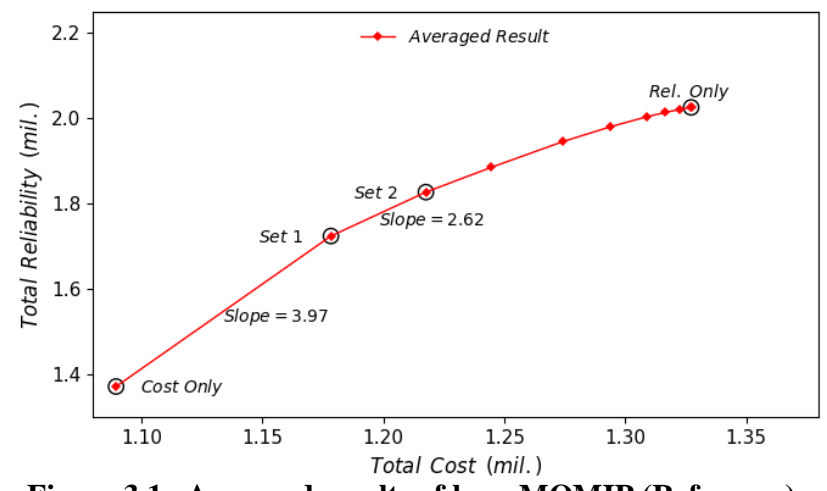

Figure 3.1 Averaged results of base MOMIP (Reference)

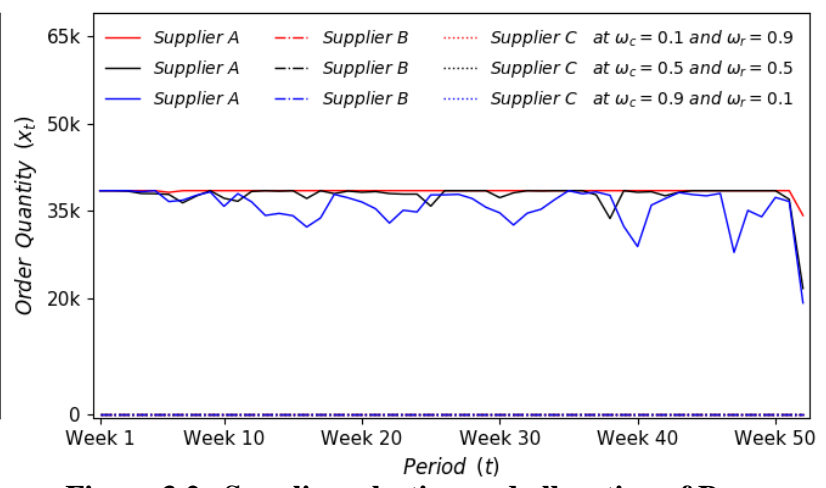

Figure 3.2 Supplier selection and allocation of Base MOMIP 


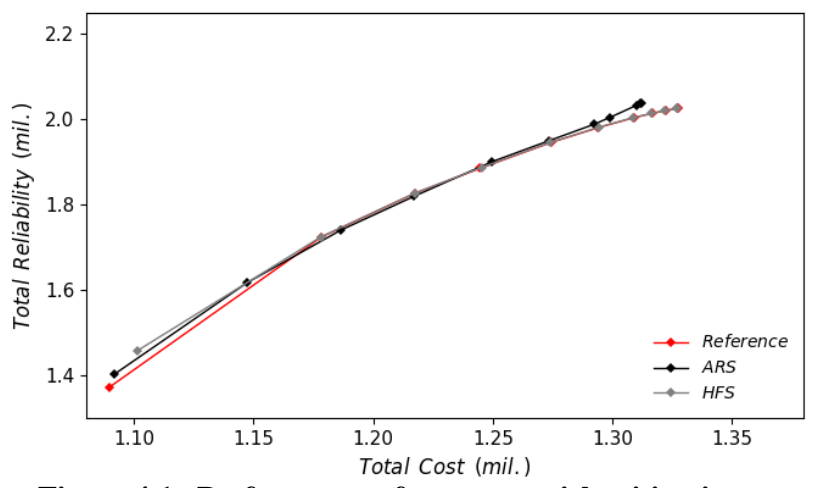

Figure 4.1 Performance of upstream risk mitigations

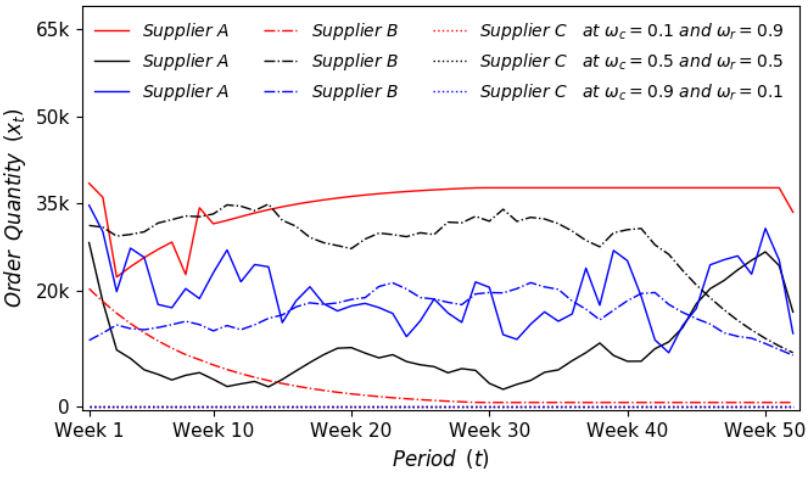

Figure 4.3 Supplier selection and allocation of ARS

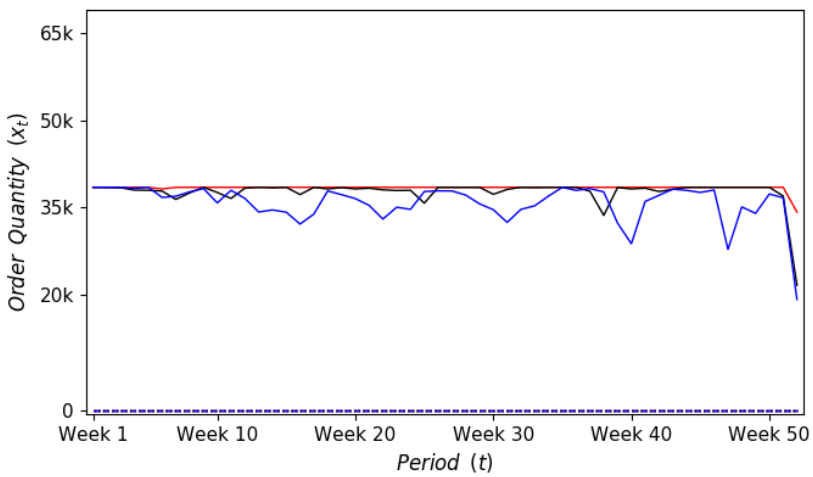

Figure 4.5 Supplier selection and allocation of HFS

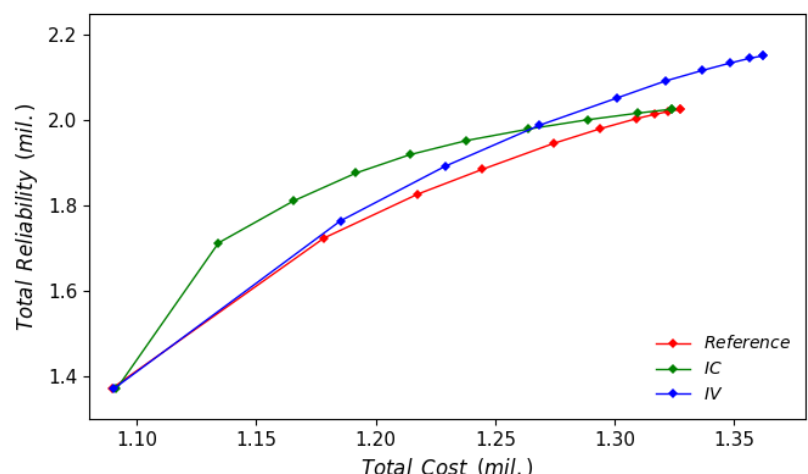

Figure 4.2 Performance of downstream risk mitigations

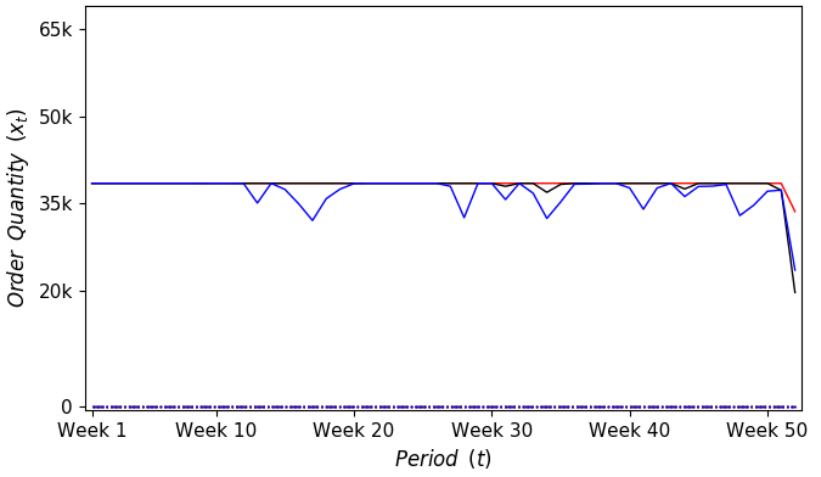

Figure 4.4 Supplier selection and allocation of IC

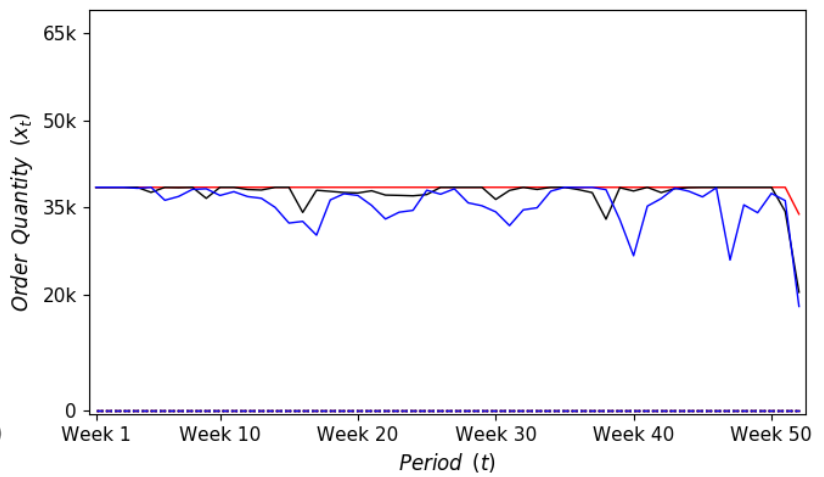

Figure 4.6 Supplier selection and allocation of IV 


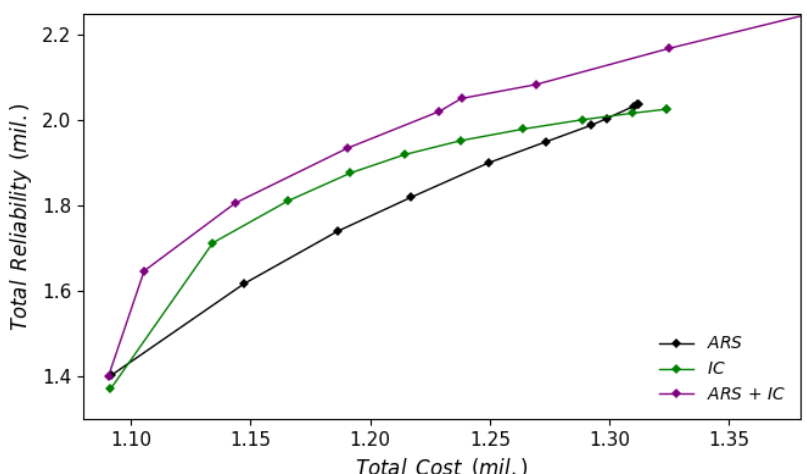

Figure 5.1 Performance of ARS + IC

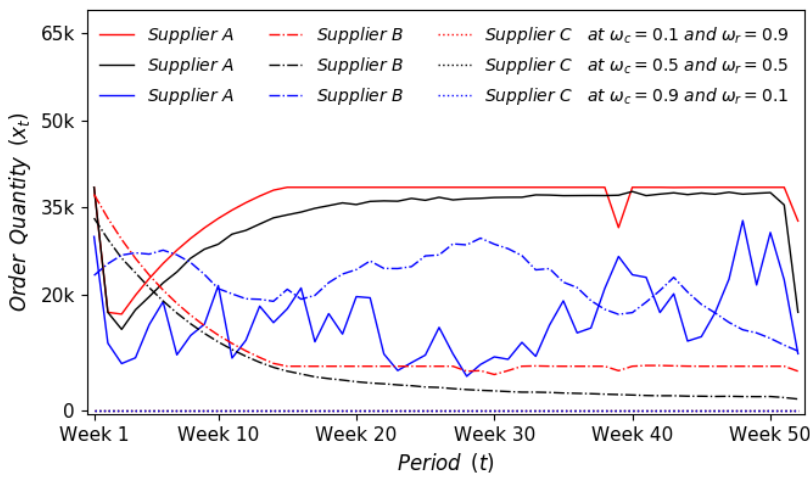

Figure 5.3 Supplier selection and allocation of ARS + IC

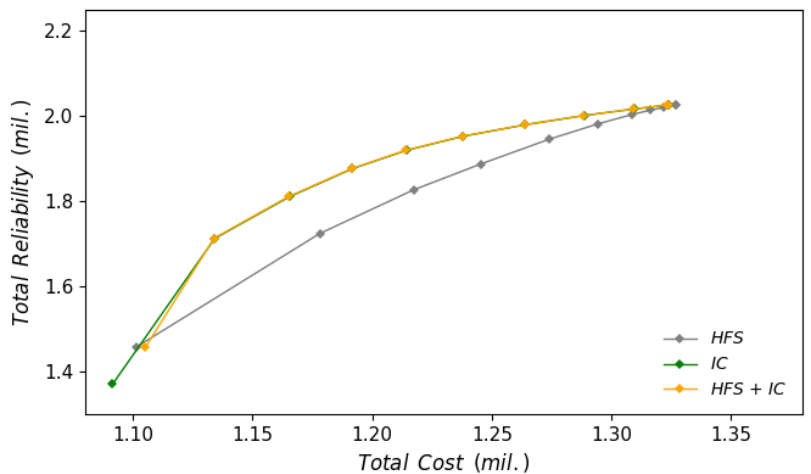

Figure 6.1 Performance of HFS + IC

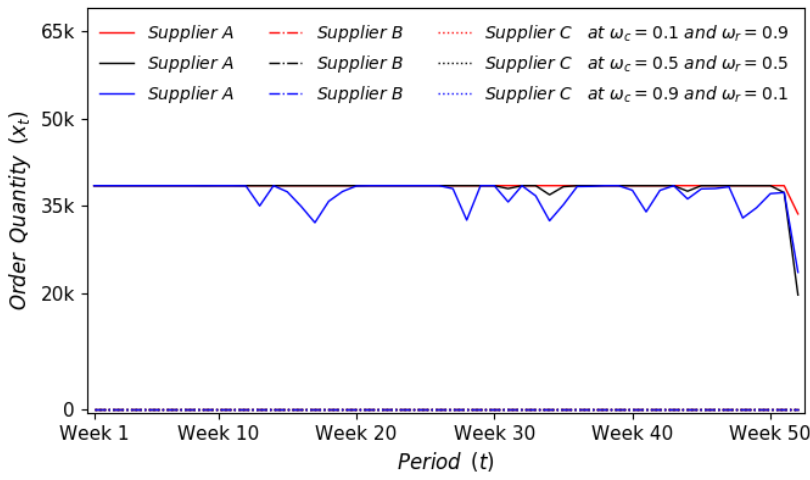

Figure 6.3 Supplier selection and allocation of HFS + IC

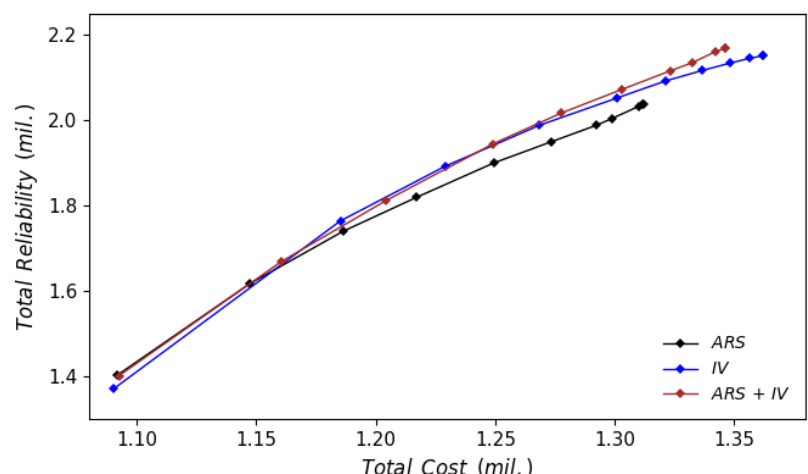

Figure 5.2 Performance of ARS + IV

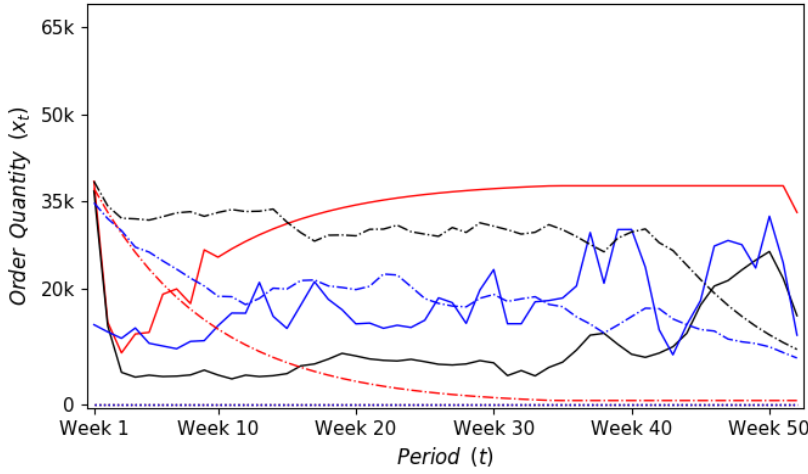

Figure 5.4 Supplier selection and allocation of ARS + IV

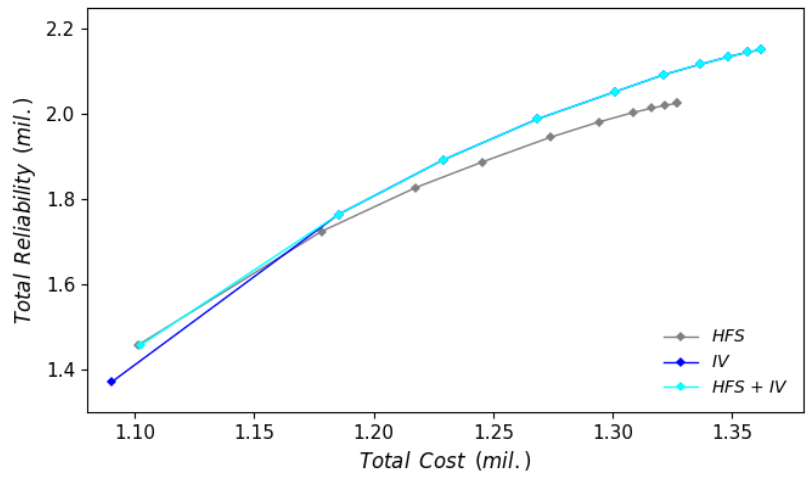

Figure 6.2 Performance of HFS + IV

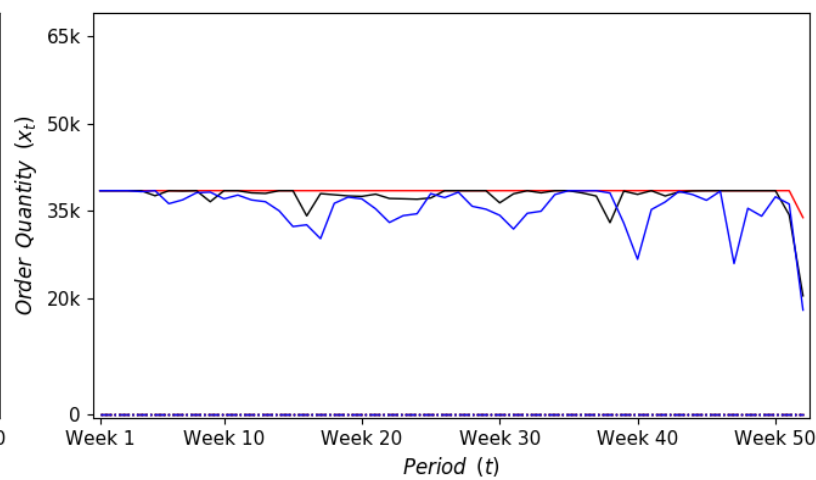

Figure 6.4 Supplier selection and allocation of HFS + IV 

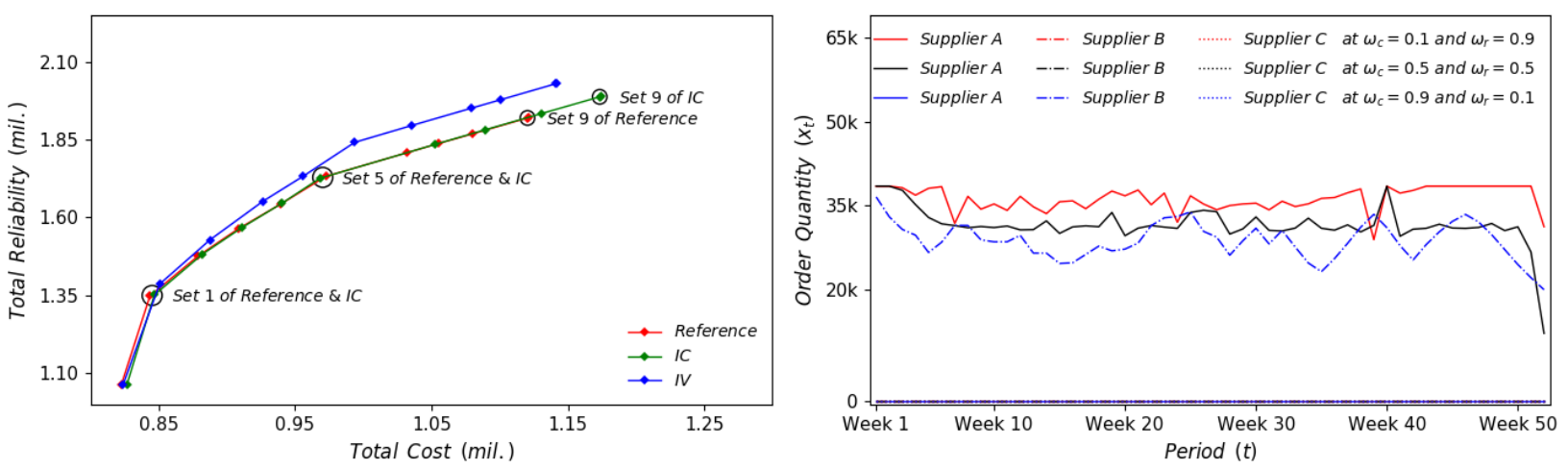

Figure 7.1 Performance of Reference, IC, and IV

Figure 7.2 Supplier selection and allocation of Reference
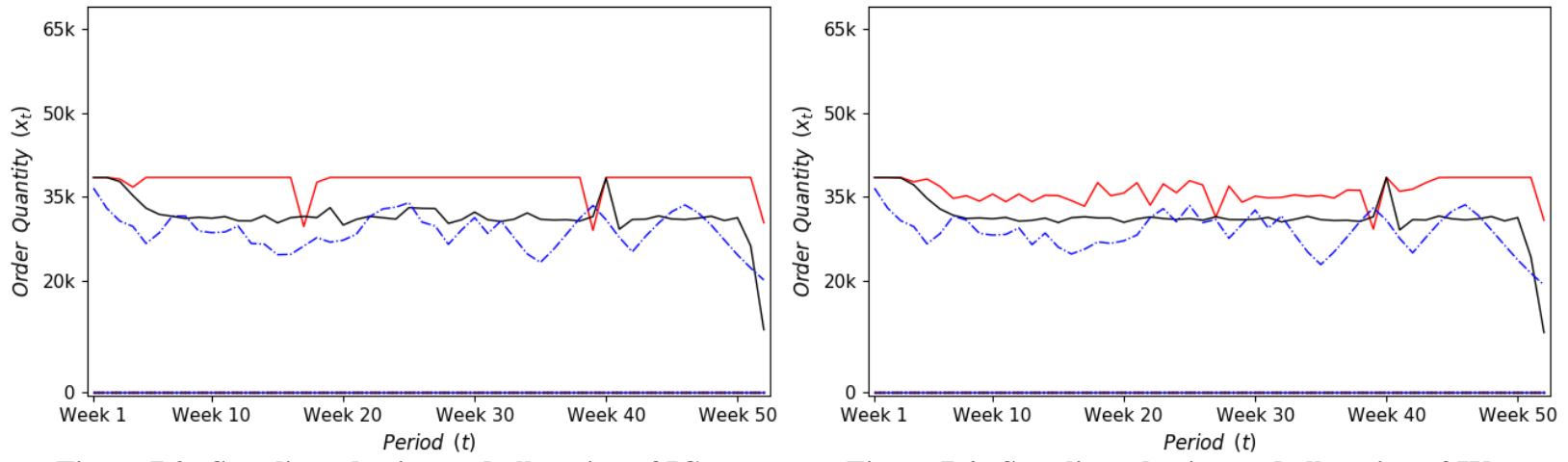

Figure 7.3 Supplier selection and allocation of IC

Figure 7.4 Supplier selection and allocation of IV 


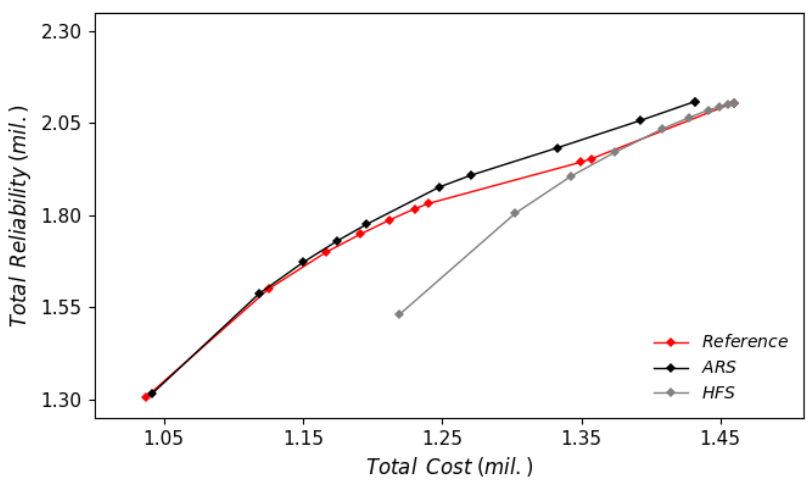

Figure 8.1 Performance of Reference, ARS, and HFS

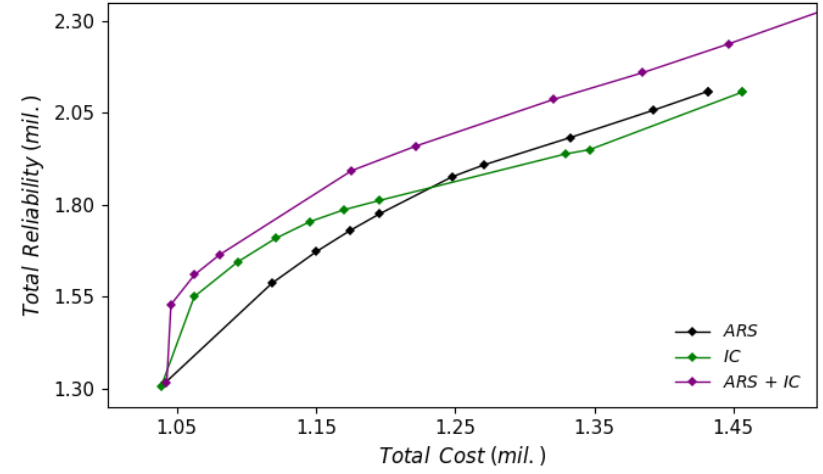

Figure 8.3 Performance of ARS + IC

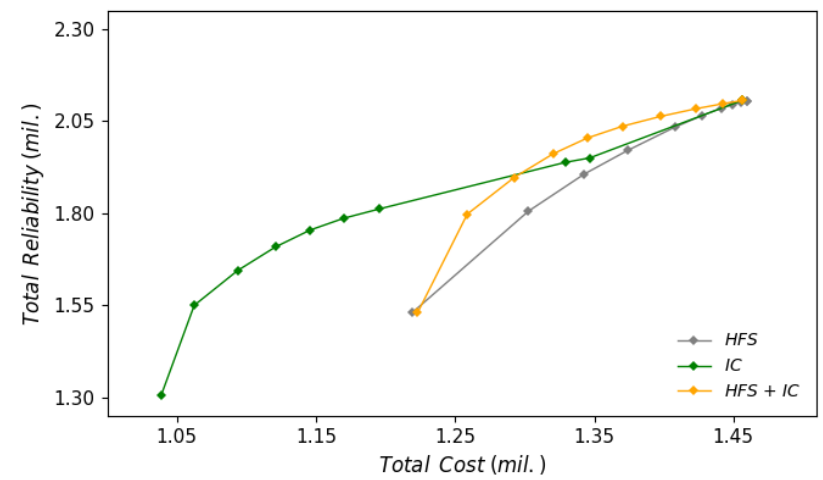

Figure 8.5 Performance of HFS + IC

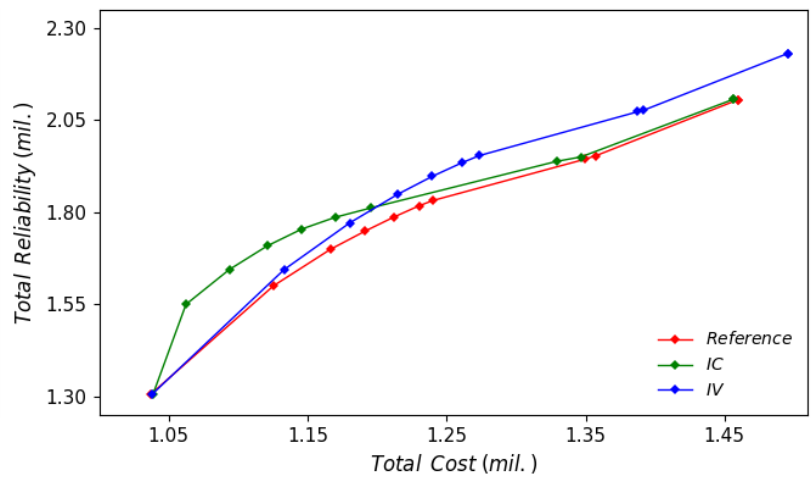

Figure 8.2 Performance of Reference, IC, and IV

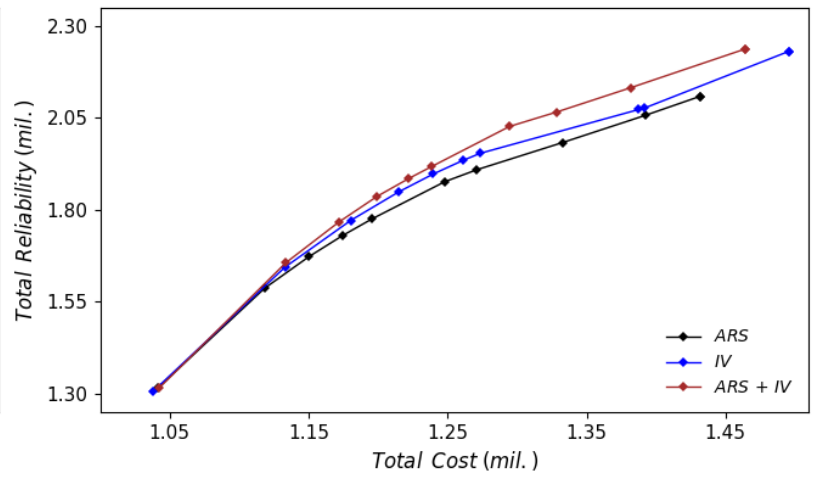

Figure 8.4 Performance of ARS + IV

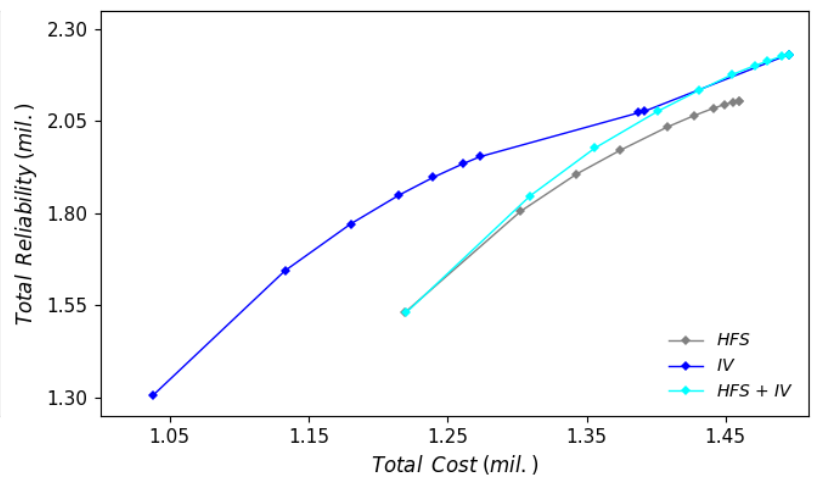

Figure 8.6 Performance of ARS + IV 


\begin{tabular}{|c|c|c|c|}
\hline Authors & Methods & Application Areas & Risk Factors Considered \\
\hline $\begin{array}{l}\text { Talluri and Narasimhan } \\
\text { (2003) }\end{array}$ & Max-min linear programming & Pharmaceutical & $\begin{array}{l}\text { Poor quality; Late deliv- } \\
\text { ery }\end{array}$ \\
\hline Kumar et al. (2006) & $\begin{array}{l}\text { Fuzzy set theory; Multi-objec- } \\
\text { tive mathematical program- } \\
\text { ming }\end{array}$ & Automotive & Uncertain capacity \\
\hline Talluri et al. (2006) & $\begin{array}{l}\text { Chance-constrained data envel- } \\
\text { opment analysis; Non-linear } \\
\text { programming }\end{array}$ & Pharmaceutical & $\begin{array}{l}\text { Poor quality; Late deliv- } \\
\text { ery }\end{array}$ \\
\hline Chan and Kumar (2007) & $\begin{array}{l}\text { Fuzzy set theory; Analytic hier- } \\
\text { archy process }\end{array}$ & Hypothetical case & $\begin{array}{l}\text { Dispersed geographical } \\
\text { location }\end{array}$ \\
\hline Kull and Talluri (2008) & $\begin{array}{l}\text { Analytic hierarchy process; } \\
\text { Goal programming }\end{array}$ & Automotive & Supplier failure \\
\hline $\begin{array}{l}\text { Lockamy III and } \\
\text { McCormack (2010) }\end{array}$ & Bayesian networks & Automotive & Supplier's financial stress \\
\hline Ravindran et al. (2010) & $\begin{array}{l}\text { Multi-objective mixed integer } \\
\text { linear programming }\end{array}$ & $\begin{array}{l}\text { Information technol- } \\
\text { ogy }\end{array}$ & Supplier failure \\
\hline $\mathrm{Wu}$ and Olson (2010) & $\begin{array}{l}\text { Data envelopment analysis; } \\
\text { Value-at-risk }\end{array}$ & Hypothetical case & Supply disruption \\
\hline Wu et al. (2010) & $\begin{array}{l}\text { Fuzzy set theory; Multi-objec- } \\
\text { tive mathematical program- } \\
\text { ming }\end{array}$ & Hypothetical case & Poor supplier service \\
\hline Meena et al. (2011) & Linear programming & Hypothetical case & Supply disruption \\
\hline Chaudhuri et al. (2013) & $\begin{array}{l}\text { Fuzzy set theory; Failure mode } \\
\text { and effect analysis; Ordered } \\
\text { weighted averaging }\end{array}$ & Aerospace & $\begin{array}{l}\text { Lack of supplier involve- } \\
\text { ment }\end{array}$ \\
\hline Chen and $\mathrm{Wu}(2013)$ & $\begin{array}{l}\text { Analytic hierarchy process; A } \\
\text { modified failure mode and ef- } \\
\text { fect analysis }\end{array}$ & Electronics & Poor supplier service \\
\hline $\begin{array}{l}\text { Ruiz-Torres et al. } \\
(2013)\end{array}$ & $\begin{array}{l}\text { Decision tree approach; Mathe- } \\
\text { matical programming }\end{array}$ & Hypothetical case & Supplier failure \\
\hline $\begin{array}{l}\text { Viswanadham and } \\
\text { Samvedi (2013) }\end{array}$ & $\begin{array}{l}\text { Fuzzy set theory; Analytic hier- } \\
\text { archy process; Technique for } \\
\text { order preference by similarity } \\
\text { to the ideal solution (TOPSIS) }\end{array}$ & Hypothetical case & Uncertain capacity \\
\hline Sawik (2014) & $\begin{array}{l}\text { Stochastic mixed integer pro- } \\
\text { gramming }\end{array}$ & Hypothetical case & Supply disruption \\
\hline Moghaddam (2015) & $\begin{array}{l}\text { Monte Carlo simulation; Goal } \\
\text { programming }\end{array}$ & Hypothetical case & Supplier's economic risk \\
\hline Fang et al. (2016) & $\begin{array}{l}\text { Multi-objective integer linear } \\
\text { programming; TOPSIS; Grey } \\
\text { relational analysis; Max-min } \\
\text { fuzzy }\end{array}$ & Hypothetical case & $\begin{array}{l}\text { Poor quality; Late deliv- } \\
\text { ery; Supply disruption }\end{array}$ \\
\hline Rao et al. (2017) & $\begin{array}{l}\text { Multi-attribute auction; Grey } \\
\text { correlation degree }\end{array}$ & Utility & $\begin{array}{l}\text { Supplier's technology } \\
\text { risk; Supplier's infor- } \\
\text { mation risk; Supplier's } \\
\text { management risk; Sup- } \\
\text { plier's economic risk; } \\
\text { Supplier's environmental } \\
\text { risk; Supplier's societal } \\
\text { risk; Supplier's ethical } \\
\text { risk }\end{array}$ \\
\hline
\end{tabular}

Table 1 Supplier selection approaches with risk consideration 


\begin{tabular}{|c|c|c|}
\hline Mitigation Strategy & $\begin{array}{c}\text { Approach/ } \\
\text { Classification }\end{array}$ & Description \\
\hline ARS & $\begin{array}{c}\text { Upstream risk mitigation/ } \\
\text { Redundancy }\end{array}$ & $\begin{array}{c}\text { Increase the number of suppliers, i.e., modify existing supply } \\
\text { base from single to dual/multiple sourcing }\end{array}$ \\
\hline HFS & $\begin{array}{c}\text { Upstream risk mitigation/ } \\
\text { Flexibility }\end{array}$ & $\begin{array}{c}\text { Replace existing supplier(s) with new supplier(s) that offer } \\
\text { more volume flexibility }\end{array}$ \\
\hline IC & $\begin{array}{c}\text { Downstream risk mitigation/ } \\
\text { Redundancy }\end{array}$ & $\begin{array}{c}\text { Increase internal production/manufacturing capacity by 20\% } \\
\text { of existing capacity }\end{array}$ \\
\hline IV & $\begin{array}{c}\text { Downstream risk mitigation/ } \\
\text { Redundancy }\end{array}$ & $\begin{array}{c}\text { Increase inventory carrying capacity by 20\% of existing in- } \\
\text { ventory carrying capacity }\end{array}$ \\
\hline
\end{tabular}

Table 2 Risk Mitigation Strategies (Chopra and Sodhi, 2004; Tomlin, 2006; Talluri et al., 2013)

\begin{tabular}{|c|c|c|c|}
\hline $\begin{array}{l}\text { Mitigation } \\
\text { Strategy }\end{array}$ & $\begin{array}{c}\text { Decision Variables } \\
\text { (Original } \rightarrow \text { Modified) }\end{array}$ & $\begin{array}{c}\text { Parameters } \\
(\text { Original } \rightarrow \text { Modified })\end{array}$ & $\begin{array}{l}\text { Modified and/or Additional Constraints } \\
\qquad \text { (Original } \rightarrow \text { Modified) }\end{array}$ \\
\hline ARS & 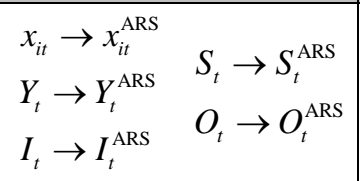 & $\begin{array}{l}R K \rightarrow R K^{\mathrm{ARS}} \\
C S \rightarrow C S^{\mathrm{ARS}}\end{array}$ & $\begin{array}{l}\sum_{i} z_{i}=N \rightarrow \sum_{i} z_{i}^{\mathrm{ARS}}=N^{\mathrm{ARS}}, \text { where } N^{\mathrm{ARS}}>N \\
\text { Additional constraint: } z_{i}^{\mathrm{ARS}} \geq z_{i}^{*}\end{array}$ \\
\hline HFS & $\begin{array}{ll}x_{i t} \rightarrow x_{i t}^{\mathrm{HFS}} & \\
Y_{t} \rightarrow Y_{t}^{\mathrm{HFS}} & S_{t} \rightarrow S_{t}^{\mathrm{HFS}} \\
I_{t} \rightarrow I_{t}^{\mathrm{HFS}} & O_{t} \rightarrow O_{t}^{\mathrm{HFS}}\end{array}$ & $\begin{array}{l}R K \rightarrow R K^{\mathrm{HFS}} \\
C S \rightarrow C S^{\mathrm{HFS}}\end{array}$ & Additional constraint: $\sum_{i} \alpha_{i} z_{i}^{\mathrm{HFS}}>\sum_{i} \alpha_{i} z_{i}^{*}$ \\
\hline IC & $\begin{array}{ll}x_{i t} \rightarrow x_{i t}^{\mathrm{IC}} & \\
Y_{t} \rightarrow Y_{t}^{\mathrm{IC}} & S_{t} \rightarrow S_{t}^{\mathrm{IC}} \\
I_{t} \rightarrow I_{t}^{\mathrm{IC}} & O_{t} \rightarrow O_{t}^{\mathrm{IC}}\end{array}$ & $\begin{array}{l}R K \rightarrow R K^{\mathrm{IC}} \\
C S \rightarrow C S^{\mathrm{IC}} \\
C A_{f} \rightarrow C A_{f}^{\mathrm{IC}}\end{array}$ & Additional constraint: $z_{i}^{\mathrm{IC}}=z_{i}^{*}$ \\
\hline IV & $\begin{array}{ll}x_{i t} \rightarrow x_{i t}^{\mathrm{IV}} & \\
Y_{t} \rightarrow Y_{t}^{\mathrm{IV}} & S_{t} \rightarrow S_{t}^{\mathrm{IV}} \\
I_{t} \rightarrow I_{t}^{\mathrm{IV}} & O_{t} \rightarrow O_{t}^{\mathrm{IV}}\end{array}$ & $\begin{array}{l}R K \rightarrow R K^{\mathrm{IV}} \\
C S \rightarrow C S^{\mathrm{IV}} \\
I U \rightarrow I U^{\mathrm{IV}}\end{array}$ & Additional constraint: $z_{i}^{\mathrm{IV}}=z_{i}^{*}$ \\
\hline \multicolumn{4}{|c|}{ Modified Cost Objective Function } \\
\hline \multicolumn{4}{|c|}{$\begin{array}{l}\min \sum_{i}\left(f_{i} z_{i}^{\kappa}+\sum_{t} c_{i} x_{i t}^{\kappa}\right)+\sum_{t}\left[h I_{t}^{\kappa}+l\left(Y_{t}^{\kappa}+O_{t}^{\kappa}\right)+p S_{t}^{\kappa}\right]+I S^{\kappa} \text {, where } I S^{\kappa} \text { is investment cost (fixed cost) for strat- } \\
\text { egy } \kappa \in\{\mathrm{IC}, \mathrm{IV}\} . B C^{\kappa} \text { and } B R^{\kappa} \text { are corresponding best possible cost and reliability when the problem of strategy } \\
\kappa \text { is solved in isolation based on cost and reliability objective functions, respectively. }\end{array}$} \\
\hline
\end{tabular}

Table 3 Modifications for sole strategy selection 


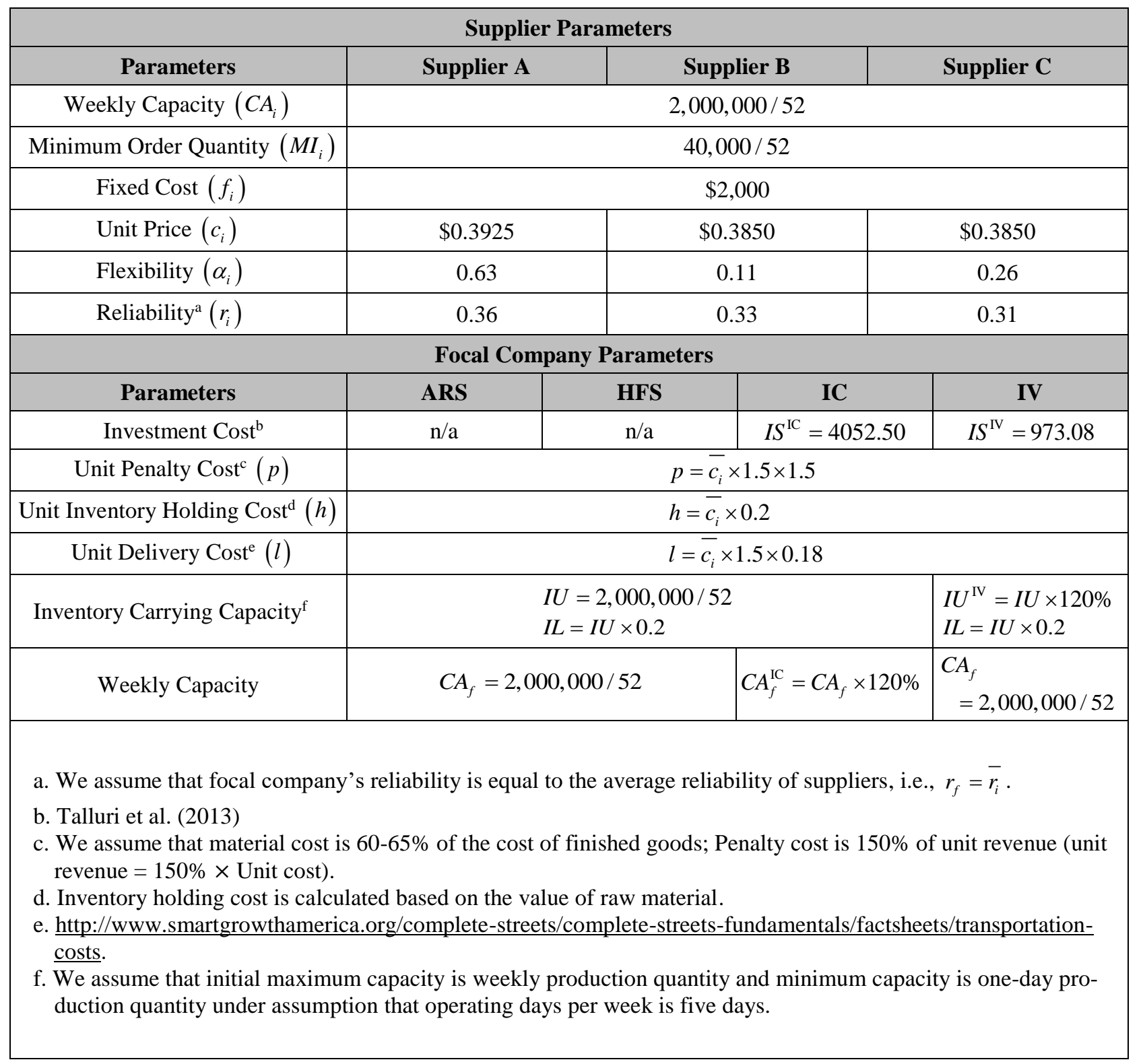

Table 4 Input Parameters

\begin{tabular}{|c|c|c|c|c|c|c|c|c|c|c|c|}
\hline & Cost Only & Set $\mathbf{1}$ & Set $\mathbf{2}$ & Set 3 & Set 4 & Set 5 & Set 6 & Set 7 & Set 8 & Set 9 & Rel. Only \\
\hline$\omega_{C}$ & 1.0 & 0.9 & 0.8 & 0.7 & 0.6 & 0.5 & 0.4 & 0.3 & 0.2 & 0.1 & 0.0 \\
\hline$\omega_{R}$ & 0.0 & 0.1 & 0.2 & 0.3 & 0.4 & 0.5 & 0.6 & 0.7 & 0.8 & 0.9 & 1.0 \\
\hline
\end{tabular}

Table 5 Weight sets

\begin{tabular}{|c|c|c|c|}
\hline \multicolumn{4}{|c|}{ Modified Supplier Parameters (Original $\rightarrow$ Modified) } \\
\hline Unit Price $\left(c_{i}\right)$ & $\$ 0.3925 \rightarrow \$ 0.45$ & $\$ 0.3850 \rightarrow \$ 0.40$ & $\$ 0.3850 \rightarrow \$ 0.35$ \\
\hline Reliability $\left(r_{i}\right)$ & $0.36 \rightarrow 0.40$ & $0.33 \rightarrow 0.325$ & $0.31 \rightarrow 0.275$ \\
\hline
\end{tabular}

Table 6 Modified supplier parameters 